NBER WORKING PAPER SERIES

\title{
DOES REMEDIAL EDUCATION AT LATE CHILDHOOD PAY OFF AFTER ALL? LONG-RUN CONSEQUENCES FOR UNIVERSITY SCHOOLING, LABOR MARKET OUTCOMES AND INTER-GENERATIONAL MOBILITY
}

\author{
Victor Lavy \\ Assaf Kott \\ Genia Rachkovski \\ Working Paper 25332 \\ http://www.nber.org/papers/w25332 \\ NATIONAL BUREAU OF ECONOMIC RESEARCH \\ 1050 Massachusetts Avenue \\ Cambridge, MA 02138 \\ December 2018
}

Special thanks go to the Social Security Administration of Israel for use of their secure research lab and for help with data in the lab. We benefitted from comments and suggestions of participants at seminars and conferences. Lavy thanks the European Research Council for financial support, through ERC Advanced Grant 323439. The views expressed herein are those of the authors and do not necessarily reflect the views of the National Bureau of Economic Research.

NBER working papers are circulated for discussion and comment purposes. They have not been peer-reviewed or been subject to the review by the NBER Board of Directors that accompanies official NBER publications.

(C) 2018 by Victor Lavy, Assaf Kott, and Genia Rachkovski. All rights reserved. Short sections of text, not to exceed two paragraphs, may be quoted without explicit permission provided that full credit, including $\odot$ notice, is given to the source. 
Does Remedial Education at Late Childhood Pay Off After All? Long-Run Consequences

for University Schooling, Labor Market Outcomes and Inter-Generational Mobility

Victor Lavy, Assaf Kott, and Genia Rachkovski

NBER Working Paper No. 25332

December 2018

JEL No. I28,J24

\section{ABSTRACT}

We analyze in this paper the long term effect of a high school remedial education program, almost two decades after its implementation. We combine high school records with National Social Security administrative data to examine longer-term outcomes when students were in their early 30s. Our evidence suggest that treated students experienced a 10 percentage points increase in completed years of college schooling, an increase in annual earnings of 4 percentage points, an increase of 1.5 percentage points in months employed, and a significant increase in intergenerational income mobility. These gains are reflecting mainly improvement in outcomes of students from below median income families. Therefore, we conclude that remedial education program that targeted underachieving students in their last year of high school had gains that went much beyond the short term significant improvements in high school matriculation exams. A cost benefit analysis of the program suggests that the government will recover its cost within 7-8 years, implying a very high rate of return to this remedial education program.

Victor Lavy

Department of Economics

University of Warwick

Coventry, CV4 7AL

United Kingdom

and Hebrew University of Jerusalem

and also NBER

v.lavy@warwick.ac.uk

Assaf Kott

Brown University

Providence, RI 02912

assafkott@gmail.com
Genia Rachkovski

Northwestern University

633 Clark St.

Evanston, IL 60208

geniar9@gmail.com 


\section{Introduction}

Remedial education programs have become a popular instrument to increase high-school matriculation and to prepare weak students for college level course work (Calcagno and Long, 2008). So far research on the casual effect of remedial programs and on its cost-effectiveness focused on short-term outcomes, mainly on test scores and high school completion. In this paper, we study the long-term effects of a remedial education program targeted for underperforming high school students, implemented in Israel in 1999-2003. Lavy and Schlosser (2005) show that this program had a large positive short term impact on treated students, causing a 13 percentage points increase in their probability of achieving a matriculation diploma at end of high school, equivalent to a 22 percent increase relative to counterfactual. Sixteen years after the program was first implemented, we set out to explore the program's effect on adulthood outcomes. Specifically, on post-secondary schooling, labor-market and personal status outcomes. The gradual implementation of the program allows us to use a propensity score matching design in which participants in the program are matched with non-participants from schools that adopted the program two years later. We observe students' outcomes every year from high school graduation (2000-2001), until age 33 (in 2015). Thus, we can estimate the treatment effects for every year in the period and trace the dynamic evolution of the program effects.

This paper contributes to the ongoing debate over the relative merit of early versus late childhood intervention with the unique perspective of investigating the effect on adulthood outcomes. By looking at how remedial education affects adulthood outcomes, this article addresses the question of whether investments in the later stages of a child's development have sustained long-term positive payoffs. Recent evidence in support of early childhood interventions is documented in Currie (2001), Currie and Thomas (2001), Krueger and Whitmore (2001), and Garces, Thomas, and Currie (2002). Carneiro and Heckman (2003) suggest that there is a consensus among practitioners in the field that early childhood interventions are preferred, mainly because it is much more difficult to improve an individual's cognitive and noncognitive abilities later in life. The evidence on high school interventions is mostly based on randomized trials in the United States, where an array of service-oriented dropout-prevention programs for American 
teens has failed to increase graduation rates (Dynarski and Gleason 1998). Our evidence in this paper, in contrast, shows positive returns at adulthood for an intervention implemented at a relatively late stage of schooling. Our research is also related to the recent debate on the effects of school inputs and expenditures on student success and achievement. For a discussion of this issue, see Carneiro and Heckman (2003). The evidence we provide in this article concerns a relatively neglected form of intervention, that of augmenting instruction time for targeted students rather than for an entire class.

To our knowledge, this is the first study to link participation in an educational remedial program in high-school to achievements in adulthood. Recent studies have mainly focused on the short-term effect of remediation programs on academic outcomes. A considerable amount of work has centered on remediation programs that were carried in elementary or high schools. On the other hand, there are some studies that examine remediation programs for college students. Both strands of the literature focused on the short-term effects of these programs. Banerjee, Cole, Duflo, \& Linden (2007) have studied a remedial program in India in which students at grade 3 or 4 received targeted instruction from an informal teacher and find that it was successful in the short run with an increase of 0.14 and 0.28 standard deviations in average test scores during the first and second year, respectively. Banerjee et al. (2010) show that a remedial education program in NGO's schools, based on carefully monitored but lightly trained community volunteers in India significantly improved the reading ability of children who attended the program. Banerjee et al. (2016) evaluate a similar scale-up randomized experiment of targeted remedial education in government schools in four Indian States and find gains in language of 0.15-0.70 standard deviations. Battistin and Schizzerotto (2012) have assessed an upper secondary remedial education summer school reform in Italy in which underperforming students had to take remedial courses over the summer. They find heterogeneous treatment effect, with mildly positive effects on performance for students enrolled in the academic track, and negative effects for students in technical and vocational oriented schools. Angrist, Lang, and Oreopoulos (2009) find that a college program combining academic support service with financial incentives had a positive effect on study skills of women with no effect on men. Martorell and McFarlin (2011) study the effect of a college remediation program and find that the program had little effect on 
academic and job-market outcomes. Scrivener et al. (2015) examines the effect of the City University of New York's Accelerated Study in Associate Program. This program required students to attend college full time and encourages them to take developmental courses. Their findings suggest that the program had a positive effect on participants' academic outcomes over the course of three-year studies.

By combining high school records with National Social Security administrative data we supplement to this literature an examination of the effects on longer-term outcomes (when students were in their early 30s) such as post-secondary schooling attainment, marriage and fertility, employment and earnings. Treated students experienced economically meaningful gains in terms of post-secondary schooling attainment. Postsecondary ever enrollment of treated students increased by 13.6 percentage points and completed years of education increased by 10 percentage points. These gains were mainly driven by gains in academic and teachers' colleges, a lower quality tier of academic institutions in Israel while there was no significant change in University schooling. Moreover, we find an increase in annual earnings of 4 percentage points and an increase of 1.5 percentage points in months employed though these estimates are less precisely estimated. We find heterogeneous treatment effects with the gains in post-secondary education and in earnings among the treated group stemming mostly from the individuals below median family income. Finally, we find a significant increase in income mobility among the treated group as compared to the control and positive effects on marriage and child birth.

The paper proceeds as follows, in section 2 we describe the remedial education program, in section 3 we present the data and in section 4 we present the identification strategy and the econometric model. In section 5 we present the results on the variety of long-term outcomes discussed above and address implications on intergenerational mobility, in section 6 we conclude.

\section{Background and the Bagrut 2000 Program}

The analysis of the short term effect presented in Lavy and Schlosser (2005) indicated that the remedial education program led to 3-4 percentage point increase in the schools' average matriculation rate and to an increase of 12 percentage points in participating students probability of earning matriculation 
certificate. The latter implies a 19 percent improvement. We first summarize below the main features of the remedial education program and then examine whether these gains were translated into economically meaningful improvements in adulthood.

Israeli post-primary education consists of junior high school (grades 7-9) and high school (grades 10-12). High school students are enrolled either in an academic track leading to a matriculation certificate (Bagrut in Hebrew) or in an alternative track leading only to a high school diploma. The Bagrut is completed by passing a series of national exams in core and elective subjects beginning in tenth grade, with more tests taken in eleventh grade and most taken in twelfth grade. Students choose to be tested at various levels of proficiency, with each test awarding from one to five credit units per subject, depending on difficulty. Some subjects are mandatory, and for many the most basic level is three credits. A minimum of 20 credits is required to qualify for a matriculation certificate. About $52 \%$ of high school graduates and $46 \%$ of members of the relevant age cohort received matriculation certificates in 2002. The Israel Ministry of Education has singled out as its top priority the need to raise the matriculation rate, especially among disadvantaged students and students in peripheral communities (Ministry of Education, Culture, and Sport 2001). The ministry instituted several programs toward this goal: achievement awards for high school students (Angrist and Lavy 2009), school incentives (Lavy 2002), teacher incentives (Lavy 2009), and the large-scale remedial education program investigated here. These initiatives provide an opportunity to gauge the effectiveness of interventions in high school. Moreover, since all the interventions were implemented during the same period and share similar goals, their effectiveness may be compared. Whereas the first three interventions cited above were aimed at improving the incentives for teachers and students, the intervention analyzed in this study is based on the concept of injecting added school resources in the form of extra instructional hours for underperforming students. The Bagrut 2000 program targets low-achieving high schools. Table A1 in the appendix presents the program timeline and Table A2 presents the number of schools and of students enrolled in the program in 2001. In its first phase, which began in October 1999, it included 10 schools. During that academic year, nine additional schools were added to the program. In the following year, there were 42 participating schools. The program continued to expand; in 2002, it 
included 130 schools. The gradual implementation was due mainly to budget constraints. Schools were enrolled into the program in no particular order, although the schools participating in the first year include a higher proportion of disadvantaged students and have lower tests scores and matriculation rates. Table A1 presents the program timeline and the dates of the matriculation examinations that constitute the basis for the pre- and post-program cohorts used in the evaluation.

The intervention included individualized instruction in small study groups of up to five students for tenth, eleventh, and twelfth graders. The aims of the intervention were (1) to design individualized instruction based on students' needs; (2) to increase the matriculation rate; (3) to enhance the scholastic and cognitive abilities, self-image, and leadership aptitudes of underperforming students. Participants were chosen by their teachers based on the likelihood of their passing the matriculation exams. Although no single quantifiable measure was used to apply this guideline, teachers were instructed to select students who had up to three potentially failing subjects. The additional tutoring was focused on these subjects; the remedial classes were held during after-school hours and were taught by the classroom teachers.

\section{The Data}

In this study we use data from administrative files for students who studied in high schools that implemented the remedial education program between 1999 and 2001. The students in the sample completed high school in 2001, and in 2015 they are adults, age 33. We use several panel datasets available from Israel's National Insurance Institute (NII). The NII is responsible for social security and mandatory health insurance in Israel. NII allows restricted access to this data in their protected research lab. The underlying data sources include: (1) the population registry data, which contains information on marital status, number of children and their birth dates; (2) NII records of postsecondary ever enrollment from 2000 through 2013 based on annual reports submitted to NII by all post-secondary education institutions, from which we calculated the number of years of post-secondary schooling ${ }^{1}$; (3) Israel Tax Authority information

\footnotetext{
${ }^{1}$ The NII, which is responsible for the mandatory health insurance tax in Israel, tracks postsecondary enrollment because students pay a lower health insurance tax rate. Postsecondary schools are therefore required to send a list of
} 
on income and earnings of employees and self-employed individuals for 2000-2015, for students and their parents; (4) NII records on post-secondary schooling until 2013, marriage and fertility data until 2016. The NII linked this data set to the students' background data that was used in Lavy and Schlosser (2005) to study the effect of the remedial education program on high school academic outcomes. This information comes from administrative records of the Ministry of Education on the universe of Israeli primary schools during the 1997-2002 school years. In addition to an individual identifier, and a school and class identifier, it also included the following family-background variables: parental schooling, number of siblings, country of birth, date of immigration if born outside of Israel, ethnicity and a variety of high school achievement measures. This file also included a treatment indicator and cohort of study. We had restricted access to this data in the NII research lab at the NII headquarters in Jerusalem.

\section{b. Post-high school outcomes}

In these data, we observe two sets of post-secondary outcomes for each of the students in our sample. First, we observe post-secondary schooling attainment, including the type of post-secondary schooling institution attended, if any, and the number of years of schooling completed in each type of institution. The post-high school outcome variables of interest are indicators of ever having enrolled in a university or in an academic college, and the number of years of schooling completed in these two types of academic institutions. Even after accounting for compulsory military service, we expect that most students who enrolled in post-high school education, including those who continued schooling beyond undergraduate studies, to have graduated by age 30 .

Second, we observe year-by-year labor market outcomes from high school graduation to 2015, including employment status, information on unemployment benefits and annual earnings. Individual earnings data come from the Israel Tax Authority (ITA). Filing tax forms in Israel is compulsory only for

enrolled students to the NII every year. For the purposes of our project, the NII Research and Planning Division constructed an extract containing the 2001-2013 enrollment status of students in our study. 
individuals with non-zero self-employment earnings but ITA has information on annual gross earnings from salaried and non-salaried employment and they transfer this information annually to NII, including number of months of work in a given year. Using this data, NII produces an annual series of total annual earnings from salaried and self-employment. Following NII practice, individuals with positive (non-zero) number of months worked and zero or missing value for earnings are assigned zero earnings. We were allowed restricted access to this data in the NII protected lab in Jerusalem.

Definitions of Outcomes in Adulthood: In this subsection, we describe the outcomes in adulthood for students in the sample.

Education. University schooling: is an indicator for being enrolled for at least one year in university schooling and years of university schooling is the number of years of attendance during the period 20002013. Academic college schooling: is an indicator for being enrolled for at least one year in any academic college and years of college schooling is the number of years of attendance. We code in a similar way the two respective outcomes for the other types of post-secondary schooling, in particular teachers colleges, vocational non-academic colleges, and other non-academic institutions

Labor Market Outcome. Earnings: Individual earnings data comes from the Israel Tax Authority (ITA). Only individuals with non-zero self-employment earnings are required to file tax returns in Israel, but the ITA has information on annual gross earnings from salaried and non-salaried employment, and they transfer this information, including the number of months of work in a given year, annually to the NII. The NII produces an annual series of total annual earnings from salaries and self-employment and we used this variable for 2000-2015. Following NII practice, individuals with a positive (non-zero) number of months of work and zero or missing value for earnings are assigned zero earnings. Three percent of individuals have such zero earnings in 2015 in our basic sample. To account for earnings data-outliers we dropped from the sample all observations that are six or more standard deviations away from the mean. Very few observations are dropped from the sample in each of the years and the results are not qualitatively affected by this sample selection procedure. The same earnings data is also available for the parents of the students 
in our sample, for the years 2000-2002 and 2008-2012. We compute the average earnings of each parent and of the household for 2000-2002 and use it as an additional control in a robustness check of the evidence presented in this paper. These data were not available for the analysis of the effect of the program on shortterm outcomes. Employment: An indicator with value 1 for individuals with non-zero number months of work in a given year, 0 otherwise. Months worked: The total number of months an individual worked in a calendric year.

Personal Status Outcomes: The data on marital status and having children is available for 2016. Marriage: is an indicator for ever being married and we also define as outcome Age at First Marriage. Children: is an indicator for having at least one child and we also define as an outcome Age at Birth of First Child. Number of Children: is the number of children until 2016.

\section{Identification and Estimation}

The average school level effect of the program may be broken down into two parts: the effect on the participants and the effect on the participants' peers through externalities and spillover. ${ }^{2}$ At the school level the natural comparison group are the schools that enrolled in the program in the following year. At the student level we do not have a natural comparison group for the treated students and therefore we resort to a model where selection is based on observables but the control group students are selected from the schools that enrolled in the following year. The central identifying assumption in this case is that treatment status is independent of potential achievements conditioned on being from a later enrolled school and on student's observable covariates and lagged achievements. Although this assumption is hardly satisfied in most non-experimental studies, choosing students from schools who enroll into the program a year later and the availability of a wealth of data on student characteristics and student achievement on matriculation

\footnotetext{
${ }^{2}$ Students in treated schools who were not in the program could have been affected in various ways. For example, the program may have freed some of the classroom teacher's time, which could then be directed to untreated students. Another possibility is that the improved learning of program participants reduced the frequency of disruptions during regular class sessions. On the other hand, negative externalities may have ensued if the close relationship between teachers and treated students that developed during treatment resulted in attention in regular classes being diverted from nonparticipants to participants.
} 
exams taken before the program was implemented make this a credible approach in our case. ${ }^{3}$ As Smith and Todd (2005) note, a critical condition for reducing selection bias is to have data containing a rich set of variables that affect both program participation and student achievement.

A comparison group was selected from among the students in the comparison schools. We avoided choosing students from treated schools because, first, they might have been exposed to treatment through potential externalities of the program and second, they might be different from program participants in observable and unobservable characteristics, as hinted by the fact that they were not chosen for the program. As a benchmark we first estimated OLS regressions in which we controlled for the following student and school covariates: gender, ethnic origin, parents' education, number of siblings, immigration status, number of matriculation credits earned in grades 10 and 11, average weighted score on these credits, school size, its square, twelfth-grade ever enrollment, religious status of school, parental earnings, and school matriculation rate in 1999. Although this method controls for a large set of covariates and preprogram achievements, we might have been comparing dissimilar populations, since the achievements for treated students would be contrasted with the achievements for the whole sample of students from comparison schools. ${ }^{4}$ An alternative approach is to implement a nonparametric matching method, as in Angrist (1998). This would assure that the subsets of students that form the treated and comparison groups have similar distributions of covariates. It also reduces the need to rely on model extrapolations and functional form. However, this procedure has a major problem in that as the number of covariates increases, the probability that both treated and comparison students will have the same set of covariates approaches zero. Rosenbaum and Rubin (1983) proposed an alternative approach that circumvents the curse of dimensionality. They

\footnotetext{
${ }^{3}$ The claim that the program itself may have changed the students' behavior and achievement on the examinations taken before participation in the program is not a concern in this case for two reasons: first, for most schools, it was the first year of implementation of the program, making it highly unlikely that the students were aware of the program before they were given the opportunity to participate. Second, the preprogram achievements are based on the matriculation examinations, which have a strong influence on opportunities for higher education and jobs. Thus, it does not stand to reason that students would risk future opportunities and underperform on these exams in order to be admitted to the program.

${ }^{4}$ Because some of the covariates are non-discrete, OLS estimates will be based on the whole sample even if for some values of the covariates there are only treated or comparison students.
} 
provide a proof that states that if treatment assignment can be ignored given $\mathrm{x}$, then it can be ignored given any balancing score that is a function of $\mathrm{x}$, in particular the propensity score. We provide more details below on the propensity matching method that we implement in this paper.

\subsection{Empirical Model}

We first specify the following linear regression model which we estimate using Ordinary Least Squares:

$$
Y_{i}=\alpha_{i}+\beta^{\prime} X_{i}+\tau \cdot T_{i}+\varepsilon_{i}
$$

Where $Y_{i}$ is the long term outcome (years of post-secondary education, earnings, etc.) of student $I, X_{i}$ is a vector of student and school characteristics, $T_{i}$ is a dummy variable indicating the treatment status of the student and $\varepsilon_{i}$ is the error term, which we cluster at the school level which is the unit of treatment. We first estimated equation (1) as an OLS regression and in a second step estimated it as a Weighed Ordinary Least Squares regression which is a mixed propensity score matching and OLS regression. ${ }^{5}$ We use the following two steps algorithm:

1. Estimating the propensity score using a Probit specification

$$
\begin{aligned}
& p_{1}\left(X_{i}\right) \equiv \operatorname{Pr}\left(T_{i}=1 \mid X_{i}\right) \\
& p_{0}\left(X_{i}\right) \equiv \operatorname{Pr}\left(T_{i}=0 \mid X_{i}\right)
\end{aligned}
$$

2. Matching treated individuals to the comparison groups using both the nearest neighbor and Kernel matching algorithms with replacement and on common support

a. Nearest neighbor matching was preformed using 3 neighbors matched on the log of the odds ratio.

b. Kernel matching was performed using the Biweight kernel function and a 0.06 bandwidth.

3. Weights were allocated to individuals in the comparison group according to the matching algorithm and normalized:

a. Nearest neighbor:

$$
\sum_{j \mid T_{j}=0} 1\left\{\log \left(\frac{P_{1}\left(X_{j}\right)}{P_{0}\left(X_{j}\right)}\right)-\log \left(\frac{P_{1}\left(X_{i}\right)}{P_{0}\left(X_{i}\right)}\right) \leq \log \left(\frac{P_{1}\left(X_{l}\right)}{P_{0}\left(X_{l}\right)}\right)-\log \left(\frac{P_{1}\left(X_{i}\right)}{P_{0}\left(X_{i}\right)}\right)\right\}=m
$$

\footnotetext{
${ }^{5}$ The entire procedure was performed in Stata using the psmatch2 function, Leuven and Sianesi(2003)
} 


$$
W_{i}=1\{m \leq 3\}
$$

b. Kernel matching:

$$
W_{j}=\frac{15}{16}\left(1-\left(\frac{p_{1}\left(X_{j}\right)-p_{1}\left(X_{i}\right)}{0.06}\right)^{2}\right)^{2}
$$

Where $i$ is the treated individual to be matched.

4. Using the same controlled regression as in the simple OLS and applying the weights calculated in (every treated individual receives $W_{i}=1$ )

$$
Y_{i}=\alpha_{i}+\beta^{\prime} X_{i}+\tau \cdot T_{i}+\varepsilon_{i}
$$

This combination of the methods of propensity score matching weighting and regression allows for enhanced robustness to misspecification, as long as the parametric model for either the propensity score or the regression functions is specified correctly, the resulting estimator for the average treatment effect is consistent. A notion discussed and termed as 'double robustness' in Robins and Ritov (1997) and Imbens (2004). ${ }^{6}$

The propensity score was estimated on the basis of all the aforementioned student covariates, including preprogram achievements, and school characteristics. We tried various specifications in which we omitted one of the preprogram achievements from the propensity score equation and checked whether the matched sample was balanced for this covariate. The similar achievement of treated and comparison students in preprogram data omitted from the propensity score equation reinforces the credibility of the assumption that treated and comparison students would have done similarly afterward, too, if the treated students had not been treated. The standard errors of the estimates of the program effects were computed using twostage bootstrap methods that preserve the clustered structure of the data. In the first stage, we sampled schools with replacement; in the second stage we sampled students with in schools. For each generated sample, we estimated a propensity score function, and we then applied matching procedures to generate the estimates. The standard errors were derived from the results obtained in these replications. For the

\footnotetext{
${ }^{6}$ See Abadie and Imbens (2002) for details regarding the use of OLS with the matching procedure weighting.
} 
theoretical context, see Davison and Hinkley (1997); for an application of this procedure, see Subramanian and Deaton (1996).

A point to emphasize is that the matching of the propensity score is not meant to emulate the selection process used in the program; it is based mainly on the same central assumption of selection on observables that underlies the linear regression. The main purpose of propensity score matching is to restrict the nonexperimental comparison group to a sample that has the same distribution of covariates as the treated students. For example, Table 1 compares the characteristics of treated and comparison students matched by nearest neighbor matching. ${ }^{7}$ A total of 1,168 students from comparison schools were matched with 1,789 treated students. We were able to find a match for every treated student. The matched comparison students were selected from all comparison schools, reinforcing the argument that treated and comparison schools have similar characteristics. The comparison of treated and matched students shows no significant differences between the two groups in any of the student or school covariates.

To identify the program effects on non-treated students, we applied the same methodology described for treated students. Non-treated students in treated schools are compared to students from comparison schools, using linear regressions and alternative matching methods.

\subsection{Descriptive Statistics}

The first year of the study (1999-2000) was a pilot in which only twelfth-grade students from a few schools participated. Therefore, the evaluation focuses on the first year of full implementation, 2000-2001. Thus, 1998-99 is considered a pretreatment year. Appendix Table A2 (reproduced from Lavy and Schlosser 2005 ) presents the treated population, 1,789 students which accounted for $28 \%$ of all $12^{\text {th }}$ grade students in the treated schools. However, this rate varied across schools, from $11 \%$ to $79 \%$, as a result of a rule that allowed each school to include up to 100 students in the program irrespective of school size. Although this

\footnotetext{
${ }^{7}$ We first limited the sample to those treated and control students having propensity scores in the region of common support. Each treated student was matched with a student from comparison schools that had the nearest propensity score. Some comparison students were matched to more than one treated student. Nevertheless, most comparison students were used a maximum of two times.
} 
rule was not strictly enforced, it led to a negative correlation between the proportion enrolled in the program and school size (see appendix Figure A1, reproduced from Figure 2 in Lavy and Schlosser 2005). Appendix Figure A2 (reproduced from Figure 4 Lavy and Schlosser 2005) show the relationship between the preprogram school matriculation rate and the program participation rate. Clearly the figure shows that there was no correlation between the program participation rate and the preprogram school matriculation rate.

Schools and students were not chosen randomly to participate in the program. However, the gradual implementation of the program offers a natural comparison group that includes schools that enrolled in the program at a later year (2001-02). Therefore, we base the identification strategy on a comparison of treated and untreated students from early and late enrolled schools into the program. The mean characteristics of the schools that enrolled later strongly resemble those of the schools that enrolled first. Since this similarity is found both for the pretreatment cohort of seniors and for the treated cohort, it provides support for our claim that, during the first few years of the program, schools were enrolled in no particular order. Appendix Table A3 (appeared as Table 2 in Lavy and Schlosser 2005) presents descriptive statistics and balancing tests based on data for the 1999 graduating cohort among two groups of schools: schools that were treated in the first year of the program (col. 1) and schools to be enrolled in the second year (col. 2). The table shows only a few minor differences between treated and comparison schools. These differences are presented in column 3 and in parenthesis we present the differences standard errors. Table 1 presents an equivalent analysis to table A3 but is based on the 2001 graduating cohort. We discuss these results in more detail in the next section and we only highlight here the same similarity between treated and comparison schools that we observed based on the pre-treatment baseline sample of the 1999 cohort. For the 2001 graduating cohort of Table 1, it is also worth emphasizing the lack of significant differences in terms of lagged achievements (number of credits earned before twelfth grade and average score), which suggests that students from treated and comparison schools had similar achievements before the program started. On the other hand, the comparison of the treated schools with all other high schools in the country (i.e., those that are neither treated nor comparison schools) reveals a very different pattern. Results not shown in the paper clearly reveal that the two groups are significantly different in almost all student characteristics. 
Student achievements during the pretreatment period were also considerably higher in this sample of other schools than in treated schools.

\subsection{Propensity Score and Treated-Comparison Group Comparison}

Table 1, columns 1-2, presents detailed summary descriptive statistics for the variables that we use in the propensity score estimation, by treated students and their matched counterparts which we use as a comparison group. In column 3 we present the respective mean differences and in parenthesis the differences standard errors. Panel A presents evidence for student's demographic characteristics. Mean mother and father years of schooling are perfectly balanced, the differences being very small (-0.18 and 0.12 ) and not statistically different from zero. This pattern of close similarity between the two groups is also evident for the number of siblings, immigration status, and gender. In panel B we report this sort of balancing tests for parental average annual earnings in 2000-2002 and their ethnic origin. Father average annual earnings in this period is 101,363 NIS in the treated group and 98,340 NIS in the comparison group, the difference of 3,022 NIS is small and not statistically different from zero. Similar evidence is seen for mother's annual earnings, and there are no significant differences in parental ethnic origin as well. We note that data on parental earnings were not available when we studied the effect of the program on short term outcomes and therefore the treatment-control group balancing evidence is additional support for the close similarity between the treatment group and the chosen control group.

In panel $\mathrm{C}$ we present evidence on lagged academic outcomes, the average score in matriculation exams taken prior to $12^{\text {th }}$ grade and number of credits gained through these exams. These two outcomes are perfectly balanced. For example, the difference between the two groups in lagged average test scores is 0.84 is about one percent of the treatment group mean and is not statistically different from zero. Panel D includes means of two school characteristics which we include in the propensity score regression, ever enrollment in $12^{\text {th }}$ grade and ever enrollment in $10^{\text {th }}$ through $12^{\text {th }}$ grades. The first of the two is better balanced with a very small treat-comparison group difference, but in both measures the difference is not statistically different from zero. 


\subsection{Extensions of Estimation Effect of Remedial Education on High School Outcomes}

In this section we present estimates of the program on end of high school matriculation diploma status. The first row of Table 2 presents estimates based on a specification that includes family earnings as an additional control variable in the Bagrut outcome regression. As noted above, the family income variable was not available at the time when Lavy and Schlosser (2005) studied the effect of the program on the Bagrut rate. We note, however, that adding these family income variables as controls leaves the results unchanged. In columns 1-3 we present the treatment effect estimates on program participants and in columns 4-6 we present the (placebo) effect of the program on non-participants from schools that participated in the program. Columns 1 and 4 present OLS estimates, columns 2 and 5 present nearest neighbor matching estimates and columns 3 and 6 present kernel matching estimates. In addition to evidence based on the full sample of participants and non-participants, we also add evidence based on stratifying the sample family income measured by median parental income in the years 2002-2002. Evidence by this sample division were not reported in Lavy and Schlosser (2005) and therefore they are new evidence presented in this paper.

Several broad conclusions can be drawn from the evidence presented in Table 2. First, using family income in the propensity score regression does not change the result that the program increased the matriculation rate of participants by 13 percentage points. Similarly, the zero effect on non-participants is unchanged as a result of this addition. Secondly, remedial education led to an increase in matriculation rates of the two sub groups defined by family income but the strongest estimated effect is on the below median family income students. The program effect on Bagrut rate of this group (panel B) increased by 20 percentage points, about 30 percent increase relative to the ex-post mean of 65 percent of the treated group. The effect on students with family income above the mean is significantly lower, as it is only 5-6 percentage points relative to an ex-post mean of 71 percent. It could be that students with above median family income could afford private tutoring, a very common practice towards the high stake matriculation exams, reducing 
the effectiveness of additional remedial instruction in school, while those below median could not afford such private tutoring.

\section{Effect of Remedial Education on Long Term Outcomes}

\subsection{Post-Secondary Schooling}

We first examine the effect of the remedial education program on post-secondary schooling attainment. Table 3 presents the treatment effect on ever enrollment and on completed years of schooling on any type of post-secondary education. In each panel we also present the means of outcome variables for the treated group. We report estimates based on an OLS regressions and on the two different methods of propensity score matching, nearest neighbor and kernel. All regressions include the original covariates used in Lavy and Schlosser (2005) and in addition also average family income in the years 2000-2002. Estimates without this additional control are very similar and therefore we report only the estimates with this control included. We present estimates of treatment effect on program participants (columns 1-3) for 2013, twelve years since high school graduation. Similarly, for non-participants, in columns 4-6.

The point estimates in the different columns of Table 3 are consistently similar across the three methods of estimation. The OLS and the two propensity score matching methods yield positive treatment effects on ever enrollment and on years of post-secondary schooling. For example, based on kernel matching, ever enrollment in post-secondary schooling in 2013 is up by a statistically significant 7.6 percentage points $(\mathrm{SE}=1.9)$ and the estimates based on the other two methods are 7.2 percent (OLS) and 8.1 percent (nearest neighbor). The effect on completed years of schooling based on kernel matching is positive and precisely measured, an effect of 0.227 years $(\mathrm{se}=0.089)$.

We also use the same three estimation strategies based on a sample of non-participant students and their matched comparison group and obtain very different results that suggest zero and statistically insignificant effects of the programs on non-participant students in schools that participated in the program. These estimates which are presented in Table 3 columns 4-6 can be viewed as placebo treatment effects 
though we can also see them as suggesting zero spillover effects within schools. The kernel matching estimate of the effect on post-secondary school ever enrollment in 2013 is $-0.007(\mathrm{se}=0.017)$ and importantly it is statistically different than the estimated effect on the treated. The kernel matching estimate of the effect on years of post-secondary schooling is $0.064(\mathrm{se}=0.074)$ and it is also statistically different then the respective treatment effect on the treated presented in column 3. Both of these placebo estimates also assure that our estimates are not driven by any school level confounders.

The overall effect on post-secondary schooling can be derived from different effects on the various types of post-secondary education institutions. Since the program was targeted to relatively under achieving students we expect to find some effect also through schools that do not confers academic degrees such as vocational and other non-academic colleges. Table 4 presents estimations of the treatment effect on completed years of schooling by various types of post-secondary education. The first type, shown in panel $\mathrm{B}$, includes the seven research universities in Israel that confer $\mathrm{BA}, \mathrm{MA}$ and $\mathrm{PhD}$ degrees. The second subsector is made up of more than 50 academic colleges that mostly confer a BA degree and predominantly offer social sciences, business and law degrees. The remainder sub-sectors are: teachers' academic colleges, vocational non-academic colleges, and other non-academic institutions. Table 4 suggests that the positive effect on post-secondary education is mainly due to increased enrollment and years of schooling in nonuniversity post-secondary schooling. The effect is largest and most significant on attainment in academiccolleges. These institutions in Israel are similar to 4-years community colleges in the US. The effect on completed years of academic college is positive and significant under all three methods. Completed years of academic college education increased by about a fifth of a year and this change is precisely measured ( $\mathrm{t}$ statistic over 4). Relative to an ex-post mean of 1.249 for the treated group in 2013 these results suggest an effect of approximately $20 \%$ increase. The respective effect on schooling in teachers, vocational and other institutions are also positive but small and not precisely measured.

The fact that the effects are concentrated on the lower end of the quality of academic education in Israel is perhaps expected since participants in the remedial education program are at the margin of passing the matriculation exams and obtaining a bagrut diploma and therefore they are also likely marginal in 
admission to post-secondary institutions, especially at one of the seven research universities where admission criterions are much higher. Furthermore, it is interesting to note that the evidence presented in Table 4 suggest a decline in years of university education of about 0.085 of a year of schooling. This implies that the program led to some change in the composition of post-secondary schooling, away from the higher quality university schooling into other, somewhat less lucrative, post-secondary institutions. Several possible explanations for this result. First, students that improve their average matriculation score can now choose more desired fields of study but in colleges and not in universities, for example law and business administration, and they might prefer it over a field of study at a university that they would have chosen otherwise, for example in humanities or social science. Second, this could be a consequence of peer effect, for example the students who are affected by the program and as a result get to attend post-secondary schooling, perhaps 'pool' their friends to attend academic colleges instead of universities that they would have attended otherwise.

In Figures 1-6, we measure the treatment effect for each year since high school graduation and trace the dynamic pattern for each of the university and college schooling outcomes. To do so, we run a separate regression for each of the outcomes and for each of the years since high school graduation. We then plot the coefficients of these regressions around a $90 \%$ confidence interval. Note that both the ever-enrolled variable and the years of schooling are cumulative variables. Hence, we expected the effects to be either flat or increasing over time.

We find that the effect on academic colleges ever enrollment rate is flat after six years. This pattern likely reflects the fact that students who do not enroll in post-secondary schooling in the first six years are unlikely to return to school later in life. In contrast, the effect on years of schooling accumulates over time. Although most of the increase happens in the first six years, the effect seems to be increasing even after 12 years since graduation. The fact that the increase keeps accumulating even 12 years after high school graduation suggests that measuring outcomes too close to high-school graduation might underestimate the long-term effects. 
The substitution over time from university into academic colleges can be seen graphically in Figures 4 and 5. The divergence starts early on, suggesting differences in the initial choice of academic institutions and it accumulate over time as students spend time in these institutions. By year 12 after high school graduation, treated students had accumulated on average 0.2 extra years of academic college education and 0.085 less years of university education than the control group.

As noted earlier, the remedial education program led also to a positive treatment effect on postsecondary schooling in other forms of post-secondary schooling. These gains follow the same dynamic pattern and timing as the gains in academic college education, reaching a pick in the increase in completed years in teachers' colleges increased by 0.06 at year 11-12 after high school graduation and an increase in non-academic schooling and vocational years of schooling of 0.025 each earlier on.

Heterogeneity of Effect of Remedial Education by Socio-Economic Background of Students: The full sample results might be masking heterogeneous effects by economic background of students. Such heterogeneity in treatment effect is relevant in this context for understanding the policy implications of our findings, in particular for considerations of targeting the remedial education treatment to sub-populations that can mostly benefit from it. In section 4.4 we reported much larger effect on the matriculation rate of students from families with below median family income and below we present results on the effect on post-secondary schooling again by stratifying the sample by family income. As noted earlier, we use average parental income in 2000-2002 as the measure of family income. In columns 4-5 of Table 4 we report estimates based on samples stratified by family income. Students with below median family income experienced an increase of 0.3 years in total post-secondary education, compared to their matched control group. This effect is coming from marginally significant increases of 0.17 and 0.09 years of education in academic college and teachers' colleges respectively. In the subgroup with above median family income we observe a gain of 0.2 years in academic college education and a decrease of 0.16 in university years of education, both are precisely measured and therefore no gain for this group's overall post-secondary schooling attainment. 


\subsection{Effect on Employment and Earnings}

We start with a graphical presentation of the dynamic impact of the remedial education program on labor market outcomes: Earnings, Employment and Months worked. For each outcome we present estimates from the two different methods of propensity score matching which we use. The labor market outcomes' data are available until 2015.

Figures 7 and 7A present the estimated effect on employment based on the nearest neighbor and kernel matching propensity score, respectively. The estimates for the first three years are not meaningful because most of the students in our sample were still in military service. In the fourth year after high school graduation, about 90 percent of the individuals in the sample were employed (according to our definition of employment, which is employed at least for one month during the year and had positive earnings). For almost all years the estimates are not precisely measured with the exception of 2006, 2010 and 2015 where the estimates are positive, $2 \%, 2.3 \%$ and $1.7 \%$ respectively, and they are statistically significant. These imprecise and inconclusive employment dynamics imply that they do not play an important role in determining the effect of the remedial education program on earnings. We gain further insight about the employment effect of the program by estimating its effect on the total number of months worked in a year. These estimates are presented in Figures 8 and $8 \mathrm{~A}$ and they are positive and significant throughout most of the period. Ignoring the first three years, the estimates for 2006 to 2012 are between 0.2 and 0.3 of a month. In 2013-2015 the estimates are smaller and no longer statistically different from zero. The small or zero effect on annual employment status is probably due to a ceiling effect given the high employment rate in Israel and in our sample as well throughout this period. The positive effect of the program on months of work suggest that the program increased the likelihood of keeping a job once employed. However, our data does not allow to test this hypothesis.

We next turn to the time series of estimated effects on annual earnings, which are presented in Figures 9 and 9A. These treatment estimates are positive throughout the period. They increase over time monotonically with the exception of 2009 and 2013. Similarly, average annual earnings in the sample also 
increase monotonically until the end of the period, from NIS 33,000 (about \$8,000) in 2005 to just below NIS 90,000 in 2015. The estimated treatment effects in 2012 and in 2015 (nearest neighbor and kernel) are significantly different from zero at the 10 percent level and are around 3,400 to 4,000 NIS. In the rest of the period the treatment effect on earnings is positive and of similar magnitude but it is less precisely measured. To improve estimation efficiency, especially given that earnings data are noisier than other outcomes, we run regressions with stacked data for several years at the later part of the study period. We present these results in Table 5, using panel data for the four last available years. The estimated effect on average annual earnings during this four-year period are as follows: the kernel earnings effect estimate is NIS 2,812 with a standard error of 1,750; the nearest neighbor earnings effect estimate is NIS 3,656 with a standard error of 1,908 . The two estimates are not statistically different and are not precisely estimated though the former is almost significant at 10 percent level of significant.

Another way of examining how significant are the gains in earnings is to focus on earnings' percentile rank as an outcome because this is a more stable and less noisy than absolute earnings. It might also capture more reliably the permanent long term effect in the labor market. For example, recent papers in the intergenerational mobility literature have shown that movements across ranks in the income distribution are uncorrelated with parental income conditional on rank at age 30 while movements in log earnings are correlated with parental income conditional on log income at age 30 - in particular, rich offspring have higher earnings growth, so that age 30 measurements are biased predictors of later-life earnings. However, the rank forecasts appear to be less biased. For example, Nybom and Stuhler (2016) show with data from Sweden that the relationship between a child's income rank and their parental income rank stabilizes by about age 30; in contrast, the relationship in log earnings is less stable. Chetty et al (2014) find a similar pattern in the US tax data, reporting that percentile rank predict well where children of different economic backgrounds will fall in the income distribution later in life. Using log earnings instead leads to inferior predictions because of the growth path expansions at the top of the income distribution. Panel D of Table 5 presents estimates of the effect of the remedial program on percentile rank of earnings, 
where the rank is computed separately for each cohort. The estimates are fully consistent with the estimated effects on earnings that are presented in Panel C, being positive but much more precisely estimated. The program increased the rank in the earning distribution by 2.12 percentiles (nearest neighbor estimate) or by 1.8 percentiles based on the kernel matching.

Turning to the effect on other labor market outcomes, the effect on months of work is positive and marginally significant and the effect on employment status is also positive though not precisely measured. The positive effect on these two employment outcomes suggest that increased employment in the extensive and intensive margin contribute to the increase in earnings and so the latter is not solely due to the increase in schooling attainment.

In columns 4-6 we present the effect on non-participants' peers in treated schools. The estimated effects on the three labor market outcomes of non-participants are smaller than the treatment effect on the treated and are imprecisely measured.

Effect on Labor Outcomes by Socio-Economic Background: The above evidence on the effect of remedial education raise the important question of which segments in the treated population benefited most from this life cycle effect on earnings and relative rank in the income distribution. In particular, from a policy perspective, it is important to know if the remedial education program was able to move up the income and rank of the students who come for the lower socio-economic segment of the studied population, namely those with below median family income. It is also important to examine if the effect on labor market outcomes by family income square with the effect on post-secondary schooling. In Table 6, we present results for the effect of remedial education on labor market outcomes based on two sub-samples, students above and below median family income. The results are similarly polar to the estimates we obtained for the effect of remedial education on post-secondary schooling. The sample of students with below median family income experienced statistically significant increase in earnings and in percentile rank with less precise positive effects on employment and months worked. The above-median family income group on the other hand shows no observable gains from the program in any of the four labor market outcomes. In 
panel E of Table 6 we present estimates of program effect on two unemployment related outcomes: whether an individual experienced a spell of unemployment in a given year (panel E) and the amount of unemployment annual benefits received (panel F). The mean unemployment rate in the sample of individuals with below median income is 11.1 percent and in the sample of above median family income it is 8.7 percent. The estimates for the two outcomes in both sub-samples are small and not significantly different from zero.

Considering all evidence presented based on samples by family income, these results suggest that remedial education was very effective for high school students who are below median socio-economic status in the sample. This group post-secondary schooling attainment improved significantly and so did their labor market outcomes, in particular employment and earnings. We note that in the context of the remedial program these students might have been those with high likelihood of failing 2-3 exams while students in the high income group had difficulties in only 1-2 matriculation subjects.

\subsection{Effect on Inter-Generational Mobility}

To shed further light on the effect of the program on earnings, in Table 7 we present estimates of its effect on intergenerational earnings mobility. A significant gain in earnings among treated children should 'loosen' the link between child and parent income, therefore enhancing intergenerational income mobility. The estimates we present in this table are from a regression of children earnings on parental earnings. Children's earnings are measured by the earnings average in 2013-2015 years since treatment and parental earnings are measured as the average family earnings in 2000-2002, while their treated children were in high school. We estimate the intergenerational income regressions separately for four different groups. We first compare the results obtained from the sample of the program participants to those in the matched control group. Secondly, we replicate this analysis for the samples of non-participants in treated schools and their control group. We then compare within each pair of samples the estimated intergenerational coefficients and use $\mathrm{F}$ tests to test whether they are significantly different. We prefer this 
approach over estimating the child-parents' income relationship while pooling the pair of samples and allowing the income mobility parameter to vary by group. This approach allows all parameters to be different for the two groups within each pair and it permits the program effect on intergenerational mobility to be more transparent.

In columns 1-3 we present estimates for sample of program participants and the control group from other schools (those who entered the program a year later) and in columns 4-6 we present estimates based on the sample of the non-participants in treated schools and their control group from other schools. Based on each sample we estimate three different regressions: in the first we use as variables the log of actual earnings of children and parents. Therefore, observations with zero child or parental earnings are dropped from the sample in this regression. In the second row we present a regression with the same specification but the variables used are residuals from regressions that control for age parents. Note that all children are of the same age so there is no need to control for their age. In the second specification the variables we use are percentile rank of children and family earnings. Here again we report results first by using actual rank and secondly using parental age-residual rank. We note that the advantage of the rank-rank regressions is that we do not drop from the sample observations with zero earnings.

A consistent pattern emerges in comparing the respective estimates that we obtain from each pair of samples. First, we note that all the four estimates that are derived based on program's participants (column 1) are much smaller than the estimates obtained from the control group sample (column 2). The regression estimate of log parental earnings on long term child earnings, noted in this literature as the elasticity of intergenerational mobility, is 0.048 in the treated group, less than half of the respective estimate (0.114) in the matched control group and the two are significantly different than each other as shown by the $\mathrm{P}$ value of F-test of difference of these two estimates (presented in column 3). The implied difference represents a sharp increase in intergenerational mobility. The regression's estimates when using ageresidual variables reported in the second row are identical to the estimates presented in the first row. 
A similar pattern is seen in the intergenerational relationship based on percentile rank (third row of the table), 0.066 in the treated group and 0.130 in the control group, and a P value for the difference between these two estimates of 0.073 . We note that the rank-rank regression includes the full sample without dropping observations with zero earnings.

In sharp contrast with the estimates presented in column 1-3, the pairwise comparison among nonparticipants yields identical intergenerational mobility estimates. The two log earnings regression parameters in the first row columns 4-5 are 0.102 and 0.106 ( $\mathrm{P}$ value for difference of these parameters $=$ 0.875). When controlling for parental age the two estimates are even more similar, 0.106 and 0.108 and the $\mathrm{P}$ value for their difference is 0.923 . The two percentile rank regression parameters are 0.139 and 0.140 (P value for difference of these parameters $=0.957)$.

In summary, the remedial education program reduced sharply the link between child and parents' income and allowed the treated children to get on a steeper trajectory of income dynamics relative to their parents. This evidence strengthens further our claim that the remedial education program led to positive effect on earnings of participants. Even though the direct estimates on earnings are not too precise, the statistically positive effect of the program on rank of participants in the earning distribution and the negative effect of the program on the intergenerational earnings elasticity form convincing evidence that the gains in the bagrut outcome which led to significant gains in post-secondary schooling, led to an increase in earnings at adulthood.

\subsection{Effect on Marriage and Fertility}

Marriage and fertility outcomes of treated individuals can be affected by their schooling and labor market outcomes through assortative matching in the marriage market. In table 8 we report results regarding the program's effect on several marriage and fertility outcomes. The marriage and fertility data is available up to the end of 2016. Seventy-two percent of the treated sample are married by 2016. Results presented in panel A, columns 1-3, show an increase in the likelihood of being married by the end of 2016 in the treated 
group, an effect ranging between 4.3 and 4.7 percent which is precisely measured in all three methods. Estimates presented in panels B and C show positive effects of the treatment on the likelihood of having children and on the number of children, these effects are marginally significant. Panels D and E show a decrease in the age of marriage and the age of birth of the first child among the treated group, though both are not precisely measured.

In table 8 columns 4-5 we present results, from stratified samples based on family income, of the effects of the program on the personal status outcomes of marriage and fertility. These estimates are fully consistent with the respective evidence of the effect on labor market outcomes which are presented in Table 6. In the sample of students with family income above the median, we find an increase in the number of children and decreases in the age of marriage and age of first birth $(0.091,-0.45,-0.516$, respectively), though these effects are only marginally significant. For the sample of students with below median family income we find a significant increase in the likelihood of being married, an increase of $7.2 \%$, without any precisely measured effects on the other personal status indicators.

\section{Conclusions}

Remedial interventions in high school are under scrutiny in most OECD countries. For example, in the US the focus is on the cost and place of remediation policies within the higher education system, given the growing demand for skilled labor (Bettinger and Long 2009, Bettinger and Baker 2011). In England this debate has gained particular relevance recently given the policy changes that require students who do not get at least a grade C in English or math in GCSE (mid high school high stake exams) to repeat exams in these subjects. However, remediation policies are often costly and their efficiency in boosting student performance has been questioned (Schwartz 2012, Van Effenterre 2017), especially given the limited evidence on the longer term outcomes. Banerjee et al (2007), Banerjee et al (2010) and Banerjee et al (2016) discuss remedial education programs and their effectiveness in developing countries, finding evidence that suggest that targeted remedial interventions can address effectively children's learning gaps. In this paper 
we study a successful remedial education program that improved short term outcomes of under achieving high school students and examine whether these gains are long lasting and whether the intervention has a high internal rate of return. We consider several long run outcomes, including continuation to higher education and subsequent labor market earnings.

The gradual implementation of the program allows us to use a propensity score matching design in which participants in the program are matched with non-participants from schools that adopted the program two years later. We combine high school records with National Social Security administrative data to examine longer-term outcomes when students were in their early 30 s. Our evidence suggest that treated students experienced economically meaningful gains as post-secondary schooling enrollment which increased by 13.6 percentage points and in completed years of education which increased by 10 percentage points. These gains were driven by gains in lower quality tier of academic institutions in Israel, mainly academic and teachers' colleges, with no significant change in university schooling. Annual earnings of treated participants increased by 4 percentage points, partly explained by an increase of 1.5 percentage points in months employed and the rest accounted by higher education. The gain in income is also shown in an increase in income mobility among the treated group as compared to the control group. We find significant heterogeneity in these treatment effects, with most of the gains occurring to students from families with below median family income.

The average cost of the program was $\$ 1,100$ per participant. Average monthly earnings of participants around age 30 was about $\$ 750$. Assuming that participants pay about 20 per cent income tax rate on these earnings suggest that the government will recover its cost within 7-8 years, implying a very high rate of return to this remedial education program. Naturally this return depends on how permanent is the effect on earnings. First, we note that we measure the effect on earnings at about age 30-31, when individuals had already completed their post-secondary schooling. Second, based on a sample of older cohorts, we find that earnings at age 30-35 is a strong predictor of earnings at an older age. Third, we estimated also a significant effect on percentile rank of individuals in the distribution of their cohort, a 
measure believed to be a more stable predictor of later life earnings (Nybom and Stuhler 2016, Chetty et al 2015). A note of caution is warranted however as this cost-benefit comparison is not taking into account possible general equilibrium consideration that might reduce the rate of return to schooling when remedial education is expanded at scale.

\section{References}

Abadie, A., and G. Imbens, "Simple and Bias-Corrected Matching Estimators for Average Treatment Effects," NBER technical working paper no. 283 (2002).

Angrist, J. D., \& Lavy, V. (2009). "The Effect of High Stakes High School Achievement Awards: Evidence from a School-Centered Randomized Trial," American Economic Review. Vol. 99, No. 4, September 2009: 1384-1414.

Angrist, J., Lang, D., \& Oreopoulos, P. (2009). "Incentives and Services for College Achievement: Evidence from a Randomized Trial Incentives and Services for College Achievement: Evidence from a Randomized Trial." American Economic Journal: Applied Economics, 1(1), 136-163.

Banerjee, A.V., Cole, S., Duflo, E., and L. Linden. (2007). Remedying Education: Evidence from Two Randomized Experiments in India. The Quarterly Journal of Economics, 122(3):1235- 1264.

Banerjee, A.V., Banerji, R., Duflo, E., Glennerster, R., and S. Khemani. (2010). "Pitfalls of Participatory Programs: Evidence from a Randomized Evaluation in Education in India." American Economic Journal: Economic Policy, 2(1):1-30.

Banerjee, A., Cole, S., Duflo, E., and Linden, L. (2007). "Remedying Education: Evidence from Two Randomized Experiments in India." Quarterly Journal of Economics, (August), 1235-1264. 
Banerjee Abhijit, Rukmini Banerji, James Berry, Esther Duflo, Harini Kannan, Shobhini Mukerji, Marc Shotland, and Michael Walton. "Mainstreaming an Effective Intervention: Evidence from Randomized Evaluations of "Teaching at the Right Level” in India", August 2016.

Battistin, E., \& Schizzerotto, A. (2012). "Threat of Grade Retention, Remedial Education and Student Achievement: Evidence from Upper Secondary Schools in Italy," (7086). Retrieved from http://papers.ssrn.com/sol3/papers.cfm?abstract id=2196751.

Bettinger, E. P., and B. T. Long (2009): “Addressing the Needs of Underprepared Students in Higher Education Does College Remediation Work?” Journal of Human resources, 44(3), 736-771.

Bettinger, E., and R. Baker (2011): “The Effects of Student Coaching in College: An Evaluation of a Randomized Experiment in Student Mentoring," Working Paper 16881, NBER.

Calcagno, J. C., \& Long, B. T. (2008). "The Impact of Postsecondary Remediation Using a Regression Discontinuity Approach: Addressing Endogenous Sorting and Noncompliance." National Bureau of Economic Research Working Paper Series, No. 14194 (April), 46.

Chetty, Raj, Nathaniel Hendren, Patrick Kline, and Emmanuel Saez, (2014) "Where is the Land of Opportunity? The Geography of Intergenerational Mobility in the United States" Quarterly Journal of Economics 129(4): 1553-1623, 2014.

De Paola, M., and V. Scoppa (2014): “The Effectiveness of Remedial Courses in Italy: a Fuzzy Regression Discontinuity Design,” Journal of Population Economics, 27(2), 365-386.

Jacob, B. A., and L. Lefgren (2004): "Remedial education and student achievement: A regressiondiscontinuity analysis," Review of economics and statistics, 86(1), 226-244.

Imbens, G. W. (2004). Nonparametric estimation of average treatment effects under exogeneity: A review. Review of Economics and statistics, 86(1), 4-29. 
Lavy, V. (2016). "Teachers' Pay for Performance in the Long-Run: The Dynamic Pattern of Treatment Effects on Students' Educational and Labor Market Outcomes in Adulthood." NBER WP, 2016.

Lavy, V. (2017). "Long Run Effects of Free School Choice: College Attainment, Employment, Earnings, and Social Outcomes at Adulthood”, NBER Working Papers Number, 2016.

Lavy, V., \& Schlosser, A. (2005). "Targeted Remedial Education for Underperforming Teenagers: Costs and Benefits." Journal of Labor Economics, 23(4), 839-874.

E. Leuven and B. Sianesi. (2003). "PSMATCH2: Stata module to perform full Mahalanobis and propensity score matching, common support graphing, and covariate imbalance testing". http://ideas.repec.org/c/boc/bocode/s432001.html. Version 4.0.11.

Martorell, P., \& McFarlin, I. (2011). "Help or Hindrance? The Effects of College Remediation on Academic and Labor Market Outcomes." Review of Economics and Statistics, 93(2), 436-454.

Nybom Martin and Jan Stuhler. "Biases in Standard Measures of Intergenerational Income Dependence”. Draft, April 1, 2016.

Robins, J., and Y. Ritov, "Towards a Curse of Dimensionality Appropriate (CODA) Asymptotic Theory for Semi-Parametric Models," Statistics in Medicine 16 (1997), 285-319.

Schwartz C. Analice "Remedial Education Programs to Accelerate Learning for All”. Global Partnership for Education, Working Paper Series on Learning, No. 11 May 1, 2012.

Scrivener, S., Weiss, M. J., Ratledge, A., Rudd, T., Sommo, C., \& Fresques, H. (2015). "Doubling Graduation Rates: Three-Year Effects of CUNY's Accelerated Study in Associate Programs (ASAP) for Developmental Education Students." MDRC. Retrieved from http://eric.ed.gov/?id=ED558511

Van Effenterre Clémentine. "Post 16 Remedial Policies: a Literature Review." Centre for Vocational Educational Research London School of Economics \& Political Science, Research Discussion Paper 005, April 2017. 
Table 1: Comparison of Mean Covariates for Treated and Matched Students - Based on Propensity Score Matching

\begin{tabular}{|c|c|c|c|}
\hline & $\begin{array}{c}\text { Treated } \\
\text { Students }\end{array}$ & $\begin{array}{l}\text { Matched } \\
\text { Students }\end{array}$ & Difference (1-2) \\
\hline \multicolumn{4}{|l|}{ A. Student's characteristics } \\
\hline Father's years of schooling & 10.37 & 10.54 & $\begin{array}{l}-0.18 \\
(0.42)\end{array}$ \\
\hline Mother's years of schooling & 10.63 & 10.76 & $\begin{array}{l}-0.12 \\
(0.51)\end{array}$ \\
\hline Number of siblings & 2.51 & 2.38 & $\begin{array}{c}0.13 \\
(0.23)\end{array}$ \\
\hline Immigration status & 0.02 & 0.02 & $\begin{array}{c}0.00 \\
(0.01)\end{array}$ \\
\hline Male & 0.42 & 0.43 & $\begin{array}{l}-0.01 \\
(0.03)\end{array}$ \\
\hline \multicolumn{4}{|l|}{$\begin{array}{l}\text { B. Parental characteristics } \\
\text { Parental Average Income }\end{array}$} \\
\hline Father's average annual income (2000-2002) & 101363 & 98340 & $\begin{array}{c}3022 \\
(8701)\end{array}$ \\
\hline Mother's average annual income (2000-2002) & 47537 & 45730 & $\begin{array}{c}1807 \\
(3435)\end{array}$ \\
\hline \multicolumn{4}{|l|}{ Parents' ethnic origin } \\
\hline Asia-Africa (excluding Ethiopia) & 0.32 & 0.33 & $\begin{array}{l}-0.01 \\
(0.04)\end{array}$ \\
\hline Former Soviet Union & 0.20 & 0.21 & $\begin{array}{c}0.00 \\
(0.05)\end{array}$ \\
\hline Ethiopia & 0.02 & 0.02 & $\begin{array}{c}0.00 \\
(0.01)\end{array}$ \\
\hline Europe-America (excluding former Soviet Union) & 0.06 & 0.06 & $\begin{array}{c}0.00 \\
(0.01)\end{array}$ \\
\hline Israel & 0.40 & 0.39 & $\begin{array}{c}0.01 \\
(0.04)\end{array}$ \\
\hline $\begin{array}{l}\text { C. Student's achievements } \\
\text { Average lagged score in matriculation exams (prior to } \\
\text { twelfth grade) }\end{array}$ & 73.43 & 72.59 & $\begin{array}{c}0.84 \\
(0.90)\end{array}$ \\
\hline Number of credit units received prior to twelfth grade & 6.84 & 6.84 & $\begin{array}{c}0.00 \\
(0.38)\end{array}$ \\
\hline \multicolumn{4}{|l|}{ D. School's characteristics } \\
\hline Enrollment in twelfth grade & 177.65 & 179.51 & $\begin{array}{c}-1.86 \\
(21.56)\end{array}$ \\
\hline Enrollment in tenth grade through twelfth grade & 544.34 & 589.92 & $\begin{array}{l}-45.58 \\
(68.11)\end{array}$ \\
\hline Number of schools & 40 & 34 & \\
\hline Number of students & 1789 & 1168 & \\
\hline \multicolumn{4}{|c|}{$\begin{array}{l}\text { Notes: The table reports descriptive statistics for treated and matched comparison students. Difference of means between } \\
\text { treated and matched students is reported in col. 3. Standard errors for the differences corrected for clustering at school level are } \\
\text { reported in parentheses. Each treated student was matched with a student from comparison schools that had the nearest } \\
\text { propensity score. Some comparison students were matched to more than one treated student. The following variables were used } \\
\text { for the estimation of the propensity score: gender, immigration status, parental schooling, number of siblings, two measures of } \\
\text { pretreatment outcomes indicating the quartile of a student's average score in matriculation exams taken before the twelfth grade } \\
\text { and the quartile of the number of credit units awarded before the twelfth grade, school matriculation rate in 1999, school's } \\
\text { religious status,school size, its square, and the number of students in the twelfth grade. }\end{array}$} \\
\hline
\end{tabular}


Table 2: Estimates of the Effect of Additional Targeted Individulaized Instruction on Bagrut Eligibility

\begin{tabular}{|c|c|c|c|c|c|c|}
\hline & \multicolumn{3}{|c|}{ Participants } & \multicolumn{3}{|c|}{ Nonparticipants } \\
\hline & OLS & $\begin{array}{c}\text { Nearest } \\
\text { Neighbor } \\
\text { Matching } \\
\end{array}$ & $\begin{array}{c}\text { Kernel } \\
\text { Matching }\end{array}$ & OLS & $\begin{array}{c}\text { Nearest } \\
\text { Neighbor } \\
\text { Matching }\end{array}$ & Kernel Matching \\
\hline & $(1)$ & $(2)$ & (3) & $(4)$ & $(5)$ & $(6)$ \\
\hline \multicolumn{7}{|l|}{ A. Full Sample } \\
\hline Mean for the treated group & & $\begin{array}{c}0.681 \\
(0.466)\end{array}$ & & & $\begin{array}{c}0.465 \\
(0.499)\end{array}$ & \\
\hline Estimate & $\begin{array}{c}0.131 \\
(0.025)\end{array}$ & $\begin{array}{c}0.131 \\
(0.017)\end{array}$ & $\begin{array}{c}0.126 \\
(0.015)\end{array}$ & $\begin{array}{c}0.006 \\
(0.017)\end{array}$ & $\begin{array}{l}-0.008 \\
(0.013)\end{array}$ & $\begin{array}{l}-0.005 \\
(0.011)\end{array}$ \\
\hline \multicolumn{7}{|c|}{ B. Below Median Family Income } \\
\hline Mean for the treated group & & $\begin{array}{c}0.654 \\
(0.476)\end{array}$ & & & $\begin{array}{c}0.372 \\
(0.484)\end{array}$ & \\
\hline Estimate & $\begin{array}{c}0.172 \\
(0.032)\end{array}$ & $\begin{array}{c}0.195 \\
(0.024)\end{array}$ & $\begin{array}{c}0.193 \\
(0.021)\end{array}$ & $\begin{array}{c}0.009 \\
(0.019)\end{array}$ & $\begin{array}{c}0.000 \\
(0.018)\end{array}$ & $\begin{array}{l}-0.003 \\
(0.016)\end{array}$ \\
\hline \multicolumn{7}{|c|}{ C. Above Median Family Income } \\
\hline Mean for the treated group & & $\begin{array}{c}0.705 \\
(0.456)\end{array}$ & & & $\begin{array}{c}0.561 \\
(0.496)\end{array}$ & \\
\hline Estimate & $\begin{array}{c}0.091 \\
(0.025)\end{array}$ & $\begin{array}{c}0.056 \\
(0.023)\end{array}$ & $\begin{array}{c}0.051 \\
(0.020)\end{array}$ & $\begin{array}{c}0.002 \\
(0.018)\end{array}$ & $\begin{array}{l}-0.013 \\
(0.018)\end{array}$ & $\begin{array}{l}-0.014 \\
(0.016)\end{array}$ \\
\hline
\end{tabular}

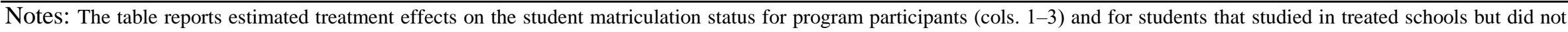

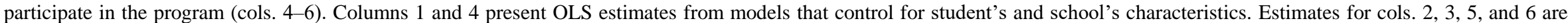

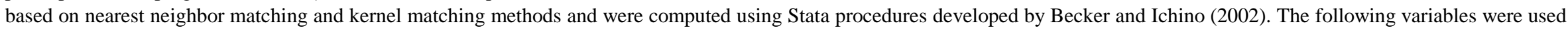

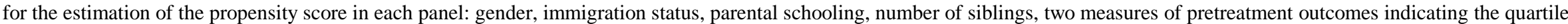

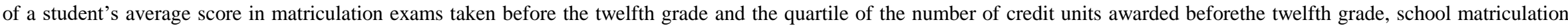

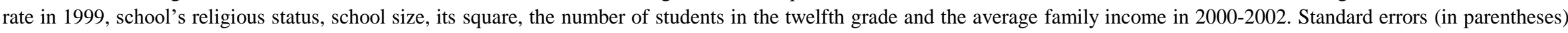

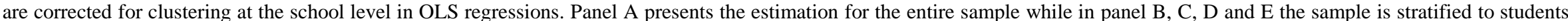

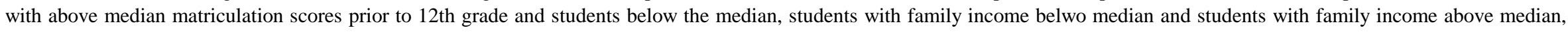
respectivly.The stratification is carried by removing the students in treated schools who don't belong to the selected group. 
Table 3: Estimates of the Effect of Additional Targeted Individulaized Instruction on Post Secondary Schooling by 2013

\begin{tabular}{|c|c|c|c|c|c|c|}
\hline & \multicolumn{3}{|c|}{ Participants } & \multicolumn{3}{|c|}{ Nonparticipants } \\
\hline & OLS & $\begin{array}{c}\text { Nearest } \\
\text { Neighbor } \\
\text { Matching } \\
\end{array}$ & $\begin{array}{c}\text { Kernel } \\
\text { Matching }\end{array}$ & OLS & $\begin{array}{c}\text { Nearest } \\
\text { Neighbor } \\
\text { Matching }\end{array}$ & Kernel Matching \\
\hline & $(1)$ & $(2)$ & (3) & $(4)$ & $(5)$ & $(6)$ \\
\hline \multicolumn{7}{|l|}{ Enrollment } \\
\hline Mean for the treated group & & $\begin{array}{c}0.631 \\
(0.483)\end{array}$ & & & $\begin{array}{c}0.508 \\
(0.500)\end{array}$ & \\
\hline Estimate & $\begin{array}{c}0.072 \\
(0.019)\end{array}$ & $\begin{array}{c}0.081 \\
(0.021)\end{array}$ & $\begin{array}{c}0.076 \\
(0.019)\end{array}$ & $\begin{array}{c}-0.003 \\
(0.016)\end{array}$ & $\begin{array}{l}-0.008 \\
(0.017)\end{array}$ & $\begin{array}{l}-0.007 \\
(0.017)\end{array}$ \\
\hline \multicolumn{7}{|l|}{ Years of Schooling } \\
\hline Mean for the treated group & & $\begin{array}{c}2.293 \\
(2.281)\end{array}$ & & & $\begin{array}{c}1.997 \\
(2.452)\end{array}$ & \\
\hline Estimate & $\begin{array}{c}0.220 \\
(0.093)\end{array}$ & $\begin{array}{c}0.231 \\
(0.093)\end{array}$ & $\begin{array}{c}0.227 \\
(0.089)\end{array}$ & $\begin{array}{c}0.087 \\
(0.074)\end{array}$ & $\begin{array}{c}0.046 \\
(0.074)\end{array}$ & $\begin{array}{c}0.064 \\
(0.074)\end{array}$ \\
\hline
\end{tabular}

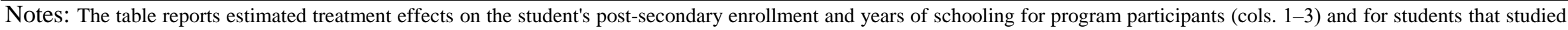

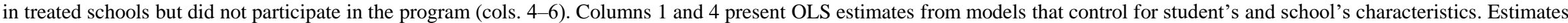

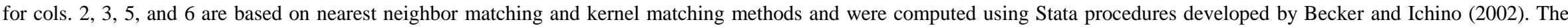

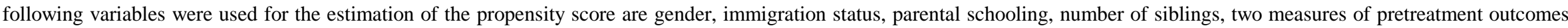

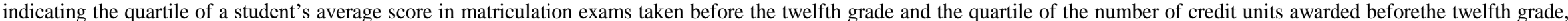

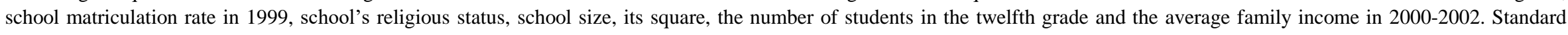
errors (in parentheses) are corrected for clustering at the school level. 
Table 4: Estimates of the Effect of Additional Targeted Individulaized Instruction on Years of Schooling by Instituation Type and by Groups by 2013

\begin{tabular}{|c|c|c|c|c|c|}
\hline & \multicolumn{3}{|c|}{$\begin{array}{l}\text { Participants } \\
\end{array}$} & \multicolumn{2}{|c|}{$\overline{\text { By Family Income (Kernel Matching) }}$} \\
\hline & OLS & $\begin{array}{c}\text { Nearest } \\
\text { Neighbor } \\
\text { Matching }\end{array}$ & $\begin{array}{c}\text { Kernel } \\
\text { Matching }\end{array}$ & Above Median & Below Median \\
\hline & (1) & (2) & (3) & (4) & (5) \\
\hline \multicolumn{6}{|l|}{ A. Post Secondary Schooling } \\
\hline Mean for the treated group & & $\begin{array}{c}2.293 \\
(2.281)\end{array}$ & & $\begin{array}{c}2.564 \\
(2.274)\end{array}$ & $\begin{array}{c}2.004 \\
(2.255)\end{array}$ \\
\hline Estimate & $\begin{array}{c}0.220 \\
(0.093)\end{array}$ & $\begin{array}{c}0.231 \\
(0.093)\end{array}$ & $\begin{array}{c}0.227 \\
(0.089)\end{array}$ & $\begin{array}{c}0.145 \\
(0.112)\end{array}$ & $\begin{array}{c}0.297 \\
(0.124)\end{array}$ \\
\hline \multicolumn{6}{|l|}{ B. University Schooling } \\
\hline Mean for the treated group & & $\begin{array}{c}0.514 \\
(1.434)\end{array}$ & & $\begin{array}{c}0.610 \\
(1.540)\end{array}$ & $\begin{array}{c}0.410 \\
(1.304)\end{array}$ \\
\hline Estimate & $\begin{array}{c}-0.080 \\
(0.064)\end{array}$ & $\begin{array}{c}-0.075 \\
(0.063)\end{array}$ & $\begin{array}{l}-0.085 \\
(0.055)\end{array}$ & $\begin{array}{l}-0.157 \\
(0.068)\end{array}$ & $\begin{array}{c}0.004 \\
(0.066)\end{array}$ \\
\hline \multicolumn{6}{|l|}{ C. College Schooling } \\
\hline Mean for the treated group & & $\begin{array}{c}1.249 \\
(1.772)\end{array}$ & & $\begin{array}{c}1.420 \\
(1.843)\end{array}$ & $\begin{array}{c}1.065 \\
(1.675)\end{array}$ \\
\hline Estimate & $\begin{array}{c}0.212 \\
(0.075)\end{array}$ & $\begin{array}{c}0.235 \\
(0.086)\end{array}$ & $\begin{array}{c}0.202 \\
(0.078)\end{array}$ & $\begin{array}{c}0.205 \\
(0.095)\end{array}$ & $\begin{array}{c}0.168 \\
(0.094)\end{array}$ \\
\hline \multicolumn{6}{|l|}{ D. Teacher Colleges } \\
\hline Mean for the treated group & & $\begin{array}{c}0.264 \\
(0.947)\end{array}$ & & $\begin{array}{c}0.266 \\
(0.954)\end{array}$ & $\begin{array}{c}0.261 \\
(0.939)\end{array}$ \\
\hline Estimate & $\begin{array}{c}0.059 \\
(0.035)\end{array}$ & $\begin{array}{c}0.060 \\
(0.040)\end{array}$ & $\begin{array}{c}0.063 \\
(0.035)\end{array}$ & $\begin{array}{c}0.032 \\
(0.044)\end{array}$ & $\begin{array}{c}0.093 \\
(0.044)\end{array}$ \\
\hline \multicolumn{6}{|c|}{ E. Vocational Two Year College } \\
\hline Mean for the treated group & & $\begin{array}{c}0.165 \\
(0.599)\end{array}$ & & $\begin{array}{c}0.160 \\
(0.550)\end{array}$ & $\begin{array}{c}0.170 \\
(0.648)\end{array}$ \\
\hline Estimate & $\begin{array}{c}0.006 \\
(0.032)\end{array}$ & $\begin{array}{c}0.026 \\
(0.033)\end{array}$ & $\begin{array}{c}0.025 \\
(0.032)\end{array}$ & $\begin{array}{c}0.040 \\
(0.032)\end{array}$ & $\begin{array}{c}0.008 \\
(0.038)\end{array}$ \\
\hline \multicolumn{6}{|l|}{ F. Other } \\
\hline Mean for the treated group & & $\begin{array}{c}0.093 \\
(0.490)\end{array}$ & & $\begin{array}{c}0.096 \\
(0.489)\end{array}$ & $\begin{array}{c}0.090 \\
(0.491)\end{array}$ \\
\hline Estimate & $\begin{array}{c}0.021 \\
(0.016)\end{array}$ & $\begin{array}{c}0.029 \\
(0.016)\end{array}$ & $\begin{array}{c}0.023 \\
(0.015)\end{array}$ & $\begin{array}{c}0.019 \\
(0.020)\end{array}$ & $\begin{array}{c}0.032 \\
(0.020)\end{array}$ \\
\hline Number of Observation & 7,008 & 4,326 & 7,006 & 3,543 & 3,462 \\
\hline
\end{tabular}


Table 5: Estimates of the Effect of Additional Targeted Individulaized Instruction on Earnings and Employment, Stacked 2012-2015

\begin{tabular}{|c|c|c|c|c|c|c|}
\hline & \multicolumn{3}{|c|}{ Participants } & \multicolumn{3}{|c|}{ Nonparticipants } \\
\hline & OLS & $\begin{array}{c}\text { Nearest } \\
\text { Neighbor } \\
\text { Matching }\end{array}$ & $\begin{array}{c}\text { Kernel } \\
\text { Matching }\end{array}$ & OLS & $\begin{array}{c}\text { Nearest } \\
\text { Neighbor } \\
\text { Matching }\end{array}$ & Kernel Matching \\
\hline & $(1)$ & $(2)$ & (3) & (4) & $(5)$ & $(6)$ \\
\hline \multicolumn{7}{|l|}{ A. Employmet } \\
\hline \multirow[t]{2}{*}{ Mean for the treated group } & & 0.897 & & & 0.878 & \\
\hline & & $(0.304)$ & & & $(0.327)$ & \\
\hline \multirow[t]{2}{*}{ Estimate } & 0.010 & 0.013 & 0.008 & -0.007 & -0.007 & -0.009 \\
\hline & $(0.008)$ & $(0.008)$ & $(0.007)$ & $(0.007)$ & $(0.007)$ & $(0.007)$ \\
\hline \multicolumn{7}{|l|}{ B. Months Worked } \\
\hline \multirow[t]{2}{*}{ Mean for the treated group } & & 9.781 & & & 9.488 & \\
\hline & & (3.964) & & & $(4.222)$ & \\
\hline \multirow[t]{2}{*}{ Estimate } & 0.173 & 0.248 & 0.143 & -0.096 & -0.093 & -0.105 \\
\hline & $(0.088)$ & $(0.095)$ & $(0.082)$ & $(0.080)$ & $(0.086)$ & $(0.085)$ \\
\hline \multicolumn{7}{|l|}{ C. Earnings (NIS) } \\
\hline \multirow[t]{2}{*}{ Mean for the treated group } & & 76913 & & & 76042 & \\
\hline & & $(62927)$ & & & (70392) & \\
\hline Estimate & $\begin{array}{c}3116 \\
(1958)\end{array}$ & $\begin{array}{c}3656 \\
(1908)\end{array}$ & $\begin{array}{c}2812 \\
(1750)\end{array}$ & $\begin{array}{c}1046 \\
(1358)\end{array}$ & $\begin{array}{c}1538 \\
(1288)\end{array}$ & $\begin{array}{c}1722 \\
(1318)\end{array}$ \\
\hline \multicolumn{7}{|c|}{ D. Percentile Ranking of Earnings } \\
\hline \multirow[t]{2}{*}{ Estimate } & 1.813 & 2.122 & 1.802 & 0.072 & 0.122 & 0.375 \\
\hline & $(0.797)$ & $(0.864)$ & $(0.751)$ & $(0.559)$ & $(0.598)$ & $(0.578)$ \\
\hline Number of Observations & 28,016 & 17,166 & 28,008 & 39,286 & 33,316 & 39,262 \\
\hline
\end{tabular}

Notes: The table reports estimated treatment effects on the student's labor market outcomes for program participants (cols. 1-3) and for students that studied in treated schools but did not

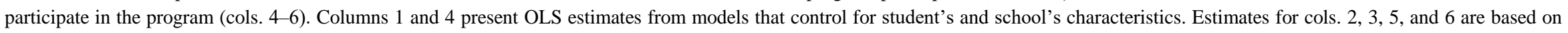
nearest neighbor matching and kernel matching methods and were computed using Stata procedures developed by Becker and Ichino (2002). The following variables were used for the estimation of the propensity score: gender, immigration status, parental schooling, number of siblings, two measures of pretreatment outcomes indicating the quartile of a student's average score in

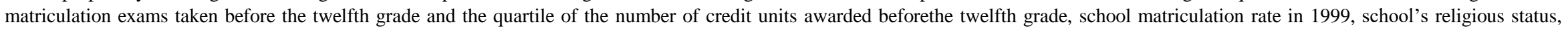
school size, its square, the number of students in the twelfth grade and the average family income in 2000-2002. Standard errors (in parentheses) are corrected for clustering at the school level. 
Table 6: Estimates of the Effect of Additional Targeted Individulaized Instruction on Employment Outcomes By Ability and Family Income, stacked 2012-2015 - Based on Kernel Matching

\begin{tabular}{|c|c|c|}
\hline & \multicolumn{2}{|c|}{ By Family Income } \\
\hline & Above Median & Below Median \\
\hline & (1) & (2) \\
\hline \multicolumn{3}{|l|}{ A. Employmet } \\
\hline Mean for the treated group & $\begin{array}{c}0.899 \\
(0.301)\end{array}$ & $\begin{array}{c}0.895 \\
(0.307)\end{array}$ \\
\hline Estimate & $\begin{array}{l}-0.003 \\
(0.010)\end{array}$ & $\begin{array}{c}0.016 \\
(0.012)\end{array}$ \\
\hline \multicolumn{3}{|l|}{ B. Months Worked } \\
\hline Mean for the treated group & $\begin{array}{c}9.860 \\
(3.910)\end{array}$ & $\begin{array}{c}9.695 \\
(4.020)\end{array}$ \\
\hline Estimate & $\begin{array}{l}-0.023 \\
(0.125)\end{array}$ & $\begin{array}{c}0.256 \\
(0.142)\end{array}$ \\
\hline \multicolumn{3}{|l|}{ C. Earnings (NIS) } \\
\hline Mean for the treated group & $\begin{array}{c}82198 \\
(66208)\end{array}$ & $\begin{array}{c}71245 \\
(58691)\end{array}$ \\
\hline Estimate & $\begin{array}{c}612 \\
(2502)\end{array}$ & $\begin{array}{c}4111 \\
(2134)\end{array}$ \\
\hline \multicolumn{3}{|c|}{ D. Percentile Ranking of Earnings } \\
\hline Estimate & $\begin{array}{c}0.856 \\
(1.030)\end{array}$ & $\begin{array}{c}2.389 \\
(1.085)\end{array}$ \\
\hline \multicolumn{3}{|c|}{ E. Annual Unemployment Insurance Benefits (Binary Indicator) } \\
\hline Mean for the treated group & $\begin{array}{c}0.087 \\
(0.282)\end{array}$ & $\begin{array}{c}0.111 \\
(0.314)\end{array}$ \\
\hline Estimate & $\begin{array}{c}-0.001 \\
(0.007)\end{array}$ & $\begin{array}{c}0.012 \\
(0.008)\end{array}$ \\
\hline \multicolumn{3}{|c|}{ F. Annual Unemployment Insurance Benefits (NIS) } \\
\hline Mean for the treated group & $\begin{array}{c}969 \\
(3766)\end{array}$ & $\begin{array}{c}1179 \\
(4114)\end{array}$ \\
\hline Estimate & $\begin{array}{l}-47 \\
(79)\end{array}$ & $\begin{array}{l}116 \\
(90)\end{array}$ \\
\hline Number of Observations & 14,176 & 13,842 \\
\hline
\end{tabular}

Notes: The table reports the hetrogenouse treatment effects on the student's labour market outcome for participats by matriculations scores prior to 12th grade and by average family income in 2000-2002. Columns 1 thru 4 present estimates based on kernel matching using Stata procedures developed by Becker and Ichino (2002). The following variables were used for the estimation of the propensity score: gender, immigration status, parental schooling, number of siblings, two measures of pretreatment outcomes indicating the quartile of a student's average score in matriculation exams taken before the twelfth grade, the quartile of the number of credit units awarded before the twelfth grade, school matriculation rate in 1999, school's religious status, school size, its square, the number of students in the twelfth grade and the average family income in 2000-2002. The stratification to boys and girls was carried by removing the students in treated schools who don't belong to the selected group. Standard errors (in parentheses) are corrected for clustering at the school level. 
Table 7: Estimates of the Effect of Additional Targeted Individulaized Instruction on Earning Mobility Outcomes Based on Kernel Matching

Individual Earnings (Avg. 2013-2015)

\begin{tabular}{cccccc}
\hline \hline & \multicolumn{2}{c}{ Participants } & \multicolumn{2}{c}{ Non Participants } \\
\hline \hline $\begin{array}{c}\text { Treated } \\
\text { Group }\end{array}$ & Control & $\begin{array}{c}\text { P-Value for Differences } \\
\text { Between Groups } \\
\text { Group }\end{array}$ & $\begin{array}{c}\text { From Treated } \\
\text { Schools }\end{array}$ & $\begin{array}{c}\text { Control } \\
\text { Group }\end{array}$ & $\begin{array}{c}\text { P-Value for Differences } \\
\text { Between Groups } \\
\text { (Chi Square in Parentheses) }\end{array}$ \\
\hline$(1)$ & $(2)$ & $(3)$ & $(4)$ & $(5)$ & $(6)$ \\
\hline
\end{tabular}

\section{$\overline{\text { Paternal Earnings (Avg. 2000-2002) }}$}

Log Wages (IGE)

$\begin{array}{cc}0.049 & 0.109 \\ (0.019) & (0.023)\end{array}$

0.037

0.102

0.106

0.875

(0.019)

(4.357)

(0.014)

(0.019)

(0.025)

Log Earnings (IGE) (Residuals on Age)

$\begin{array}{cc}0.048 & 0.114 \\ (0.019) & (0.024)\end{array}$

0.028

0.106

0.108

0.923

$(0.019)$

(4.819)

(0.014)

(0.019)

(0.009)

Percentile Ranking

$\begin{array}{ccc}0.066 & 0.130 & 0.073 \\ (0.026) & (0.025) & (3.207)\end{array}$

0.139

0.140

0.957

$-(0.025)$

(3.069

(0.015)

(0.020)

(0.003)

Percentile Ranking (Residuals on Age)

$\begin{array}{ccc}0.071 & 0.135 & 0.069 \\ (0.025) & (0.025) & (3.314)\end{array}$

0.143

0.144

0.977

$(0.025)$

(0.015)

(0.020)

(0.001)

Number of Observations

1,435

4,036

3,590

4,036

Notes: The table reports the differences between the treated and matched control groups in estimated earning mobility as measured by regressing parental earnings on individual earnings. We exclude individuals that have 0 as their or the father's avg. earnings. Columns 1-2 and 4-5 present regression estimates of the average income of the fathers of the students in our sample in 2000-2002 on the individual earnings of the students in 2013-2015. Columns 1 displays results for the treated group and column 2 presents results for the matched control group based on kernel matching using Stata procedures developed by Becker and Ichino (2002). Column 4 presents results for students that studied in treated schools but did not participate in the program and column 5 the results for their matched control group using kernel matching. Columns 3 and 6 present the p value and the Chi squared of the test comparing the mobility coefficient between the treated and control groups. The following variables were used for the estimation of the propensity score: gender, immigration status, parental schooling, number of siblings, two measures of pretreatment outcomes indicating the quartile of a student's average score in matriculation exams taken before the twelfth grade, the quartile of the number of credit units awarded before the twelfth grade, school matriculation rate in 1999, school's religious status, school size, its square, the number of students in the twelfth grade and the average family income in 2000-2002. Standard errors (in parentheses) are corrected for clustering at the school level. 
Table 8: Estimates of the Effect of Additional Targeted Individulaized Instruction on Marriage and Fertility

\begin{tabular}{|c|c|c|c|c|c|}
\hline & \multicolumn{3}{|c|}{ Participants } & \multicolumn{2}{|c|}{ By Family Income } \\
\hline & & \multirow{2}{*}{ 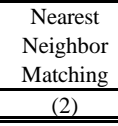 } & \multirow{2}{*}{$\begin{array}{c}\begin{array}{c}\text { Kernel } \\
\text { Matching }\end{array} \\
(3) \\
\end{array}$} & Above Median & Below Median \\
\hline & $(1)$ & & & (4) & (5) \\
\hline \multicolumn{6}{|l|}{ A. Married (Binary Indicator) } \\
\hline Mean for the treated group & & $\begin{array}{c}0.720 \\
(0.449)\end{array}$ & & $\begin{array}{c}0.717 \\
(0.451)\end{array}$ & $\begin{array}{c}0.722 \\
(0.448)\end{array}$ \\
\hline \multirow[t]{2}{*}{ Estimate } & 0.043 & 0.044 & 0.047 & 0.020 & 0.072 \\
\hline & $(0.015)$ & $(0.021)$ & $(0.018)$ & $(0.022)$ & $(0.024)$ \\
\hline \multicolumn{6}{|c|}{ B. Children (Binary Indicator) } \\
\hline \multirow[t]{2}{*}{ Mean for the treated group } & & 0.726 & & 0.719 & 0.734 \\
\hline & & $(0.446)$ & & $(0.450)$ & $(0.442)$ \\
\hline \multirow[t]{2}{*}{ Estimate } & 0.035 & 0.033 & 0.032 & 0.027 & 0.038 \\
\hline & $(0.015)$ & $(0.021)$ & $(0.019)$ & $(0.024)$ & $(0.022)$ \\
\hline \multicolumn{6}{|l|}{ C. Number of Children } \\
\hline \multirow[t]{2}{*}{ Mean for the treated group } & & 2.073 & & 2.010 & 2.139 \\
\hline & & $(0.949)$ & & $(0.923)$ & $(0.971)$ \\
\hline \multirow[t]{2}{*}{ Estimate } & 0.050 & 0.047 & 0.064 & 0.091 & 0.051 \\
\hline & $(0.039)$ & $(0.042)$ & $(0.036)$ & $(0.051)$ & $(0.043)$ \\
\hline \multicolumn{6}{|l|}{ D. Age at First Marriage } \\
\hline \multirow[t]{2}{*}{ Mean for the treated group } & & 26.391 & & 26.732 & 26.030 \\
\hline & & $(3.223)$ & & $(3.145)$ & $(3.267)$ \\
\hline \multirow[t]{2}{*}{ Estimate } & -0.275 & -0.286 & -0.310 & -0.450 & -0.212 \\
\hline & $(0.132)$ & $(0.229)$ & $(0.214)$ & $(0.243)$ & $(0.224)$ \\
\hline \multicolumn{6}{|l|}{ E. Age at First Child } \\
\hline Mean for the treated group & & $\begin{array}{l}27.833 \\
(3.201)\end{array}$ & & $\begin{array}{l}28.250 \\
(3.087)\end{array}$ & $\begin{array}{l}27.395 \\
(3.261)\end{array}$ \\
\hline Estimate & $\begin{array}{l}-0.276 \\
(0.149)\end{array}$ & $\begin{array}{l}-0.262 \\
(0.239)\end{array}$ & $\begin{array}{l}-0.303 \\
(0.226)\end{array}$ & $\begin{array}{l}-0.516 \\
(0.247)\end{array}$ & $\begin{array}{l}-0.158 \\
(0.238)\end{array}$ \\
\hline Number of Observations & 7,008 & 4,326 & 7,006 & 3,543 & 3,462 \\
\hline \multicolumn{6}{|c|}{$\begin{array}{l}\text { Notes: The table reports estimated treatment effects on demographic outcomes for program participants. Column } 1 \text { presents OLS estimates from models } \\
\text { that control for student's and school's characteristics. Estimates for cols. } 2 \text { and } 3 \text { are based on nearest neighbor matching and kernel matching methods } \\
\text { and were computed using Stata procedures developed by Becker and Ichino (2002). The following variables were used for the estimation of the } \\
\text { propensity score: gender, immigration status, parental schooling, number of siblings, two measures of pretreatment outcomes indicating the quartile of a } \\
\text { student's average score in matriculation exams taken before the twelfth grade and the quartile of the number of credit units awarded before the twelfth } \\
\text { grade, school matriculation rate in } 1999 \text {, school's religious status, school size, its square, the number of students in the twelfth grade, and average family } \\
\text { income in 2000-2002. Columns 4-7 presents estimated treatment effect using kernel matching for a stratified sample using student's average score in } \\
\text { matriculation exams taken before the twelfth grade as a measure of ability and average parental income in 2000-2002 as a measure of family income. } \\
\text { Standard errors (in parentheses) are corrected for clustering at the school level. }\end{array}$} \\
\hline
\end{tabular}


Tabel A1 - Program Time line

\begin{tabular}{|c|c|c|c|c|c|c|c|c|c|}
\hline & $\begin{array}{l}\text { June } \\
1999\end{array}$ & $\begin{array}{c}\text { October } \\
1999\end{array}$ & $\begin{array}{c}\text { January } \\
2000\end{array}$ & $\begin{array}{l}\text { June } \\
2000\end{array}$ & $\begin{array}{l}\text { October } \\
2000\end{array}$ & $\begin{array}{l}\text { April } \\
2001\end{array}$ & $\begin{array}{l}\text { June } \\
2001\end{array}$ & $\begin{array}{c}\text { October } \\
2001\end{array}$ & $\begin{array}{c}\text { January } \\
2002\end{array}$ \\
\hline $\begin{array}{l}\text { Number of schools } \\
\text { joining the program }\end{array}$ & & 10 & 9 & & 23 & 24 & & 34 & 33 \\
\hline & & \multicolumn{4}{|c|}{ Treatment group (40 schools) } & & & $\begin{array}{c}\text { Comparison } \\
\text { group }\end{array}$ & \\
\hline \multirow[t]{2}{*}{ matriculation } & + & & & + & & & + & & \\
\hline & $\begin{array}{c}\text { Pre- } \\
\text { treatment } \\
\text { outcomes }\end{array}$ & & & & & & $\begin{array}{c}\text { Post- } \\
\text { treatment } \\
\text { outcomes }\end{array}$ & & \\
\hline
\end{tabular}

Notes: Notes: Two treatment schools have been excluded from the analysis. One school is missing in the scores dataset from 1999, leaving us with no pre-treatment outcomes. The second school did not provide any data about the program implementation. As a result, we cannot identify the program participants or infer the proportion of students participating in the program in that school. The inclusion of this school in the estimation of the program effects at the school level did not change the magnitude or precision of the results. 
Table A2: Number and Proportion of Participants in the Bagrut 2001 Program

\begin{tabular}{|l|c|c|c|c|c|}
\hline \hline \multicolumn{1}{|c|}{} & \multicolumn{2}{|c|}{ Program participation rate } \\
\cline { 2 - 6 } & $\begin{array}{c}\text { Number } \\
\text { of } \\
\text { students } \\
\text { in treated } \\
\text { schools }\end{array}$ & $\begin{array}{c}\text { Number } \\
\text { of } \\
\text { program } \\
\text { participa } \\
\text { nts }\end{array}$ & Mean & Min & Max \\
\hline $10^{\text {th }}-12^{\text {th }}$ grade & 20,094 & 4,117 & $20 \%$ & $7 \%$ & $71 \%$ \\
\hline $12^{\text {th }}$ grade & 6,450 & 1,789 & $28 \%$ & $11 \%$ & $79 \%$ \\
\hline
\end{tabular}


Table A3 : Comparison of Mean Covariates and Outcomes for the Pretreatment Year (1999), Treated and Comparison

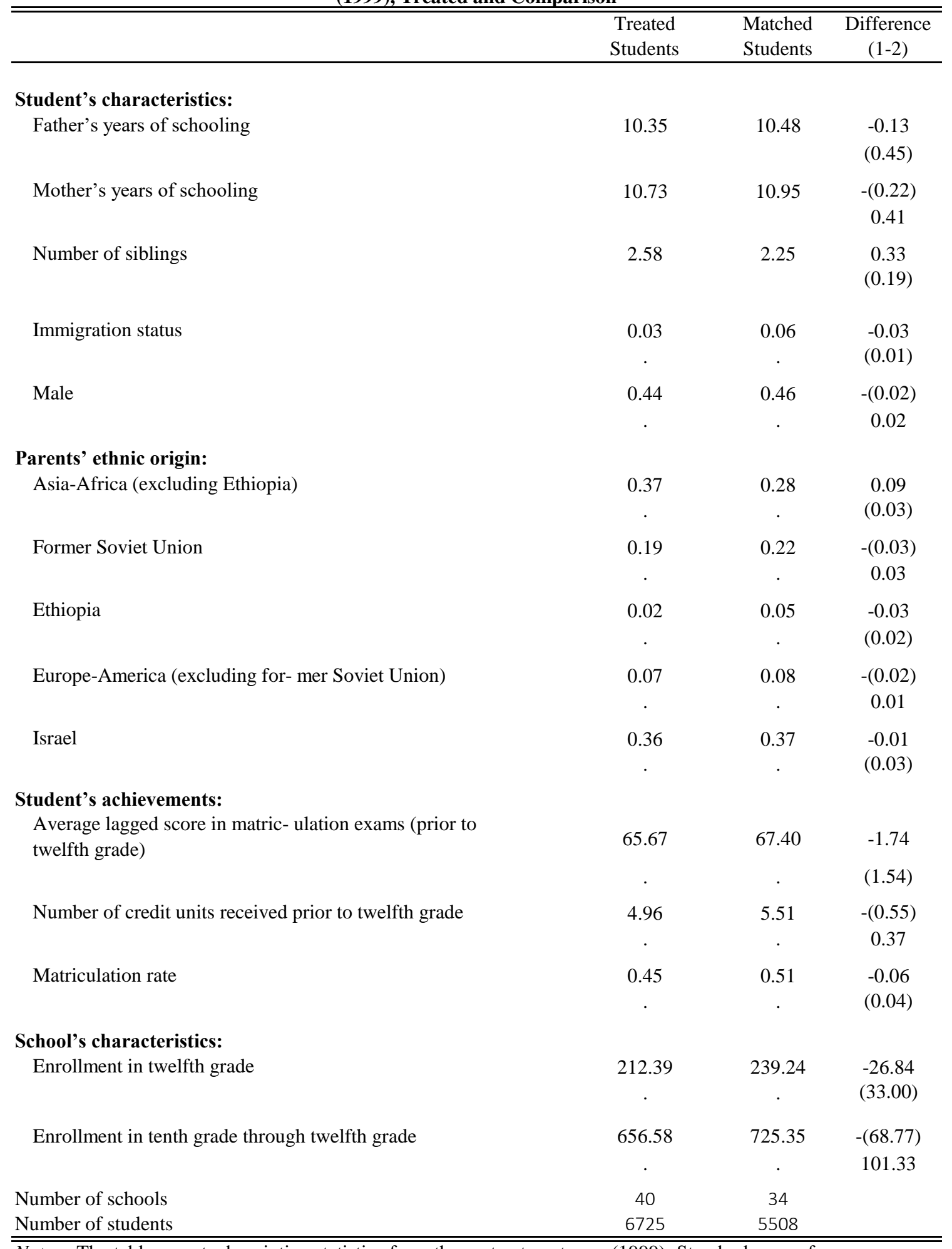

Notes: The table reports descriptive statistics from the pretreatment year (1999). Standard errors for the differences corrected for clustering at the school level are reported in parentheses. 
Table A4: Differences in Matriculation Rate Trends between Treated and Comparison Schools for Pretreatment Years, 1996-99

\begin{tabular}{lcc}
\hline \hline Regressor & Unweighted & Weighted \\
\hline \hline & $(1)$ & $(2)$ \\
Treatment x 1997 & -0.037 & -0.016 \\
& $(0.058)$ & $(0.065)$ \\
Treatment x 1998 & 0.010 & 0.016 \\
& $(0.056)$ & $(0.067)$ \\
Treatment x 1999 & -0.023 & 0.008 \\
& $(0.050)$ & $(0.059)$ \\
Number of Schools & & 67 \\
\hline \hline
\end{tabular}

Notes: The table reports the interaction coefficients between treatment status and year dummies. The dependent variable is the school matriculation rate. The additional regressors are year dummies and a treatment status dummy. Data are aggregated at the school level. Estimates in col. 2 are weighted by cohort size. Robust standard errors are in parentheses. Seven schools missing in the test scores datasets for years 1996-98 are not included in the sample. 
Figure 1: Mean and Treatment Effect: Any Post-Secondary Schooling Enrollment (Nearest Neighbor)

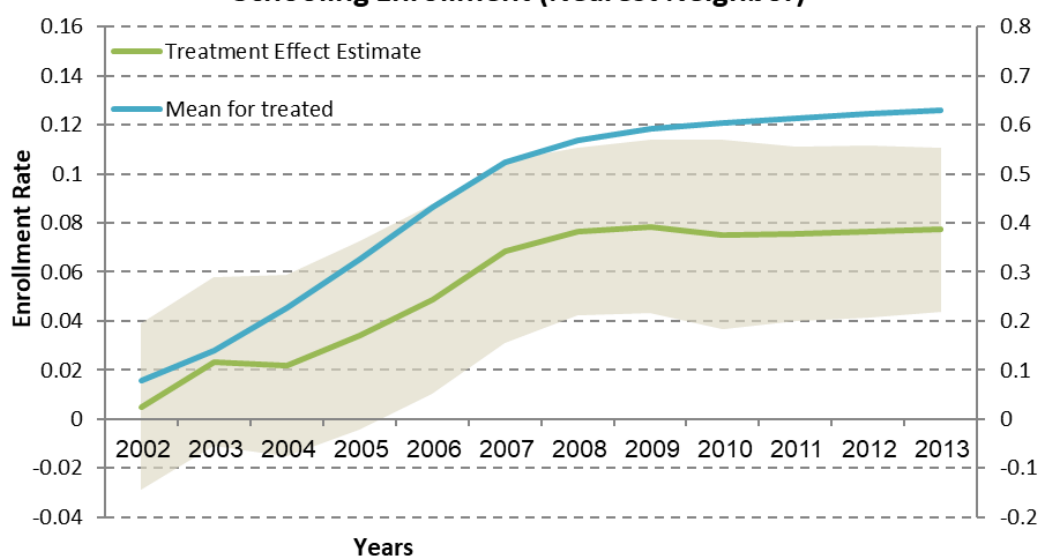

*Shaded area indicates two sided confidence intervals, $10 \%$ significance level.

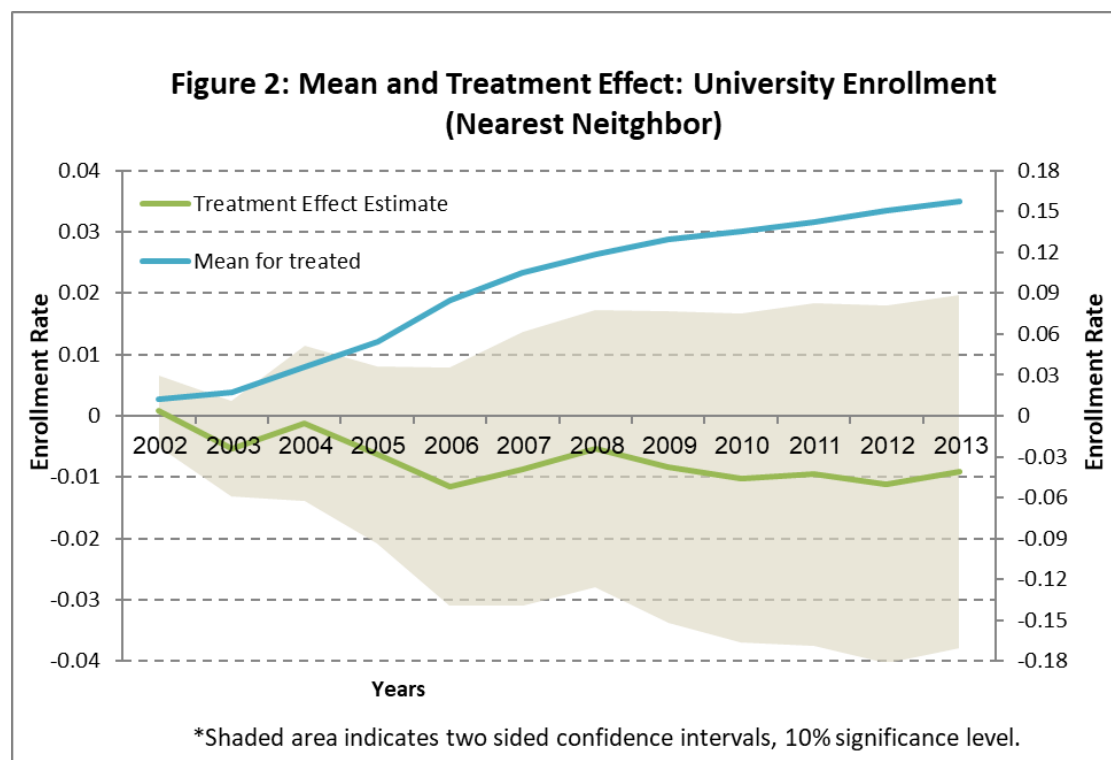

Figure 1A: Mean and Treatment Effect: Any Post-Secondary Schooling Enrollment (Kernel Matching)

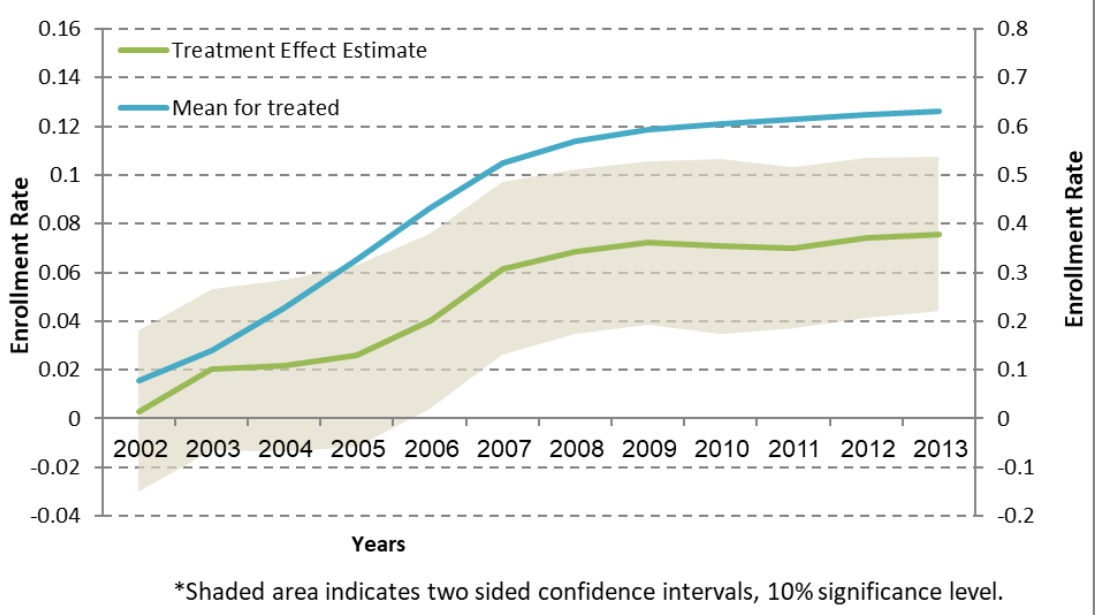

Figure 2A: Mean and Treatment Effect: University Enrollment (Kernel Matching)

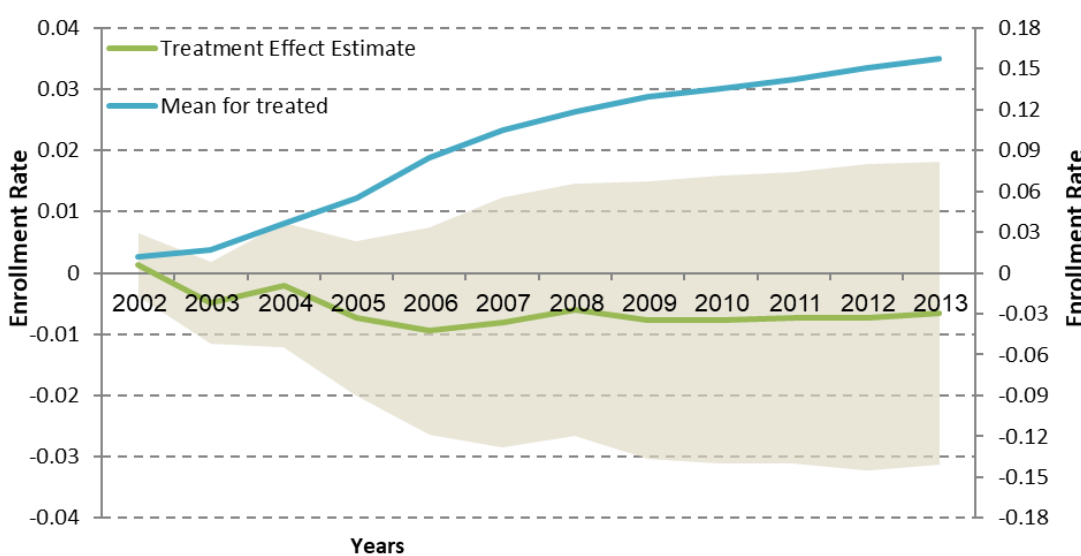

*Shaded area indicates two sided confidence intervals, 10\% significance level. 


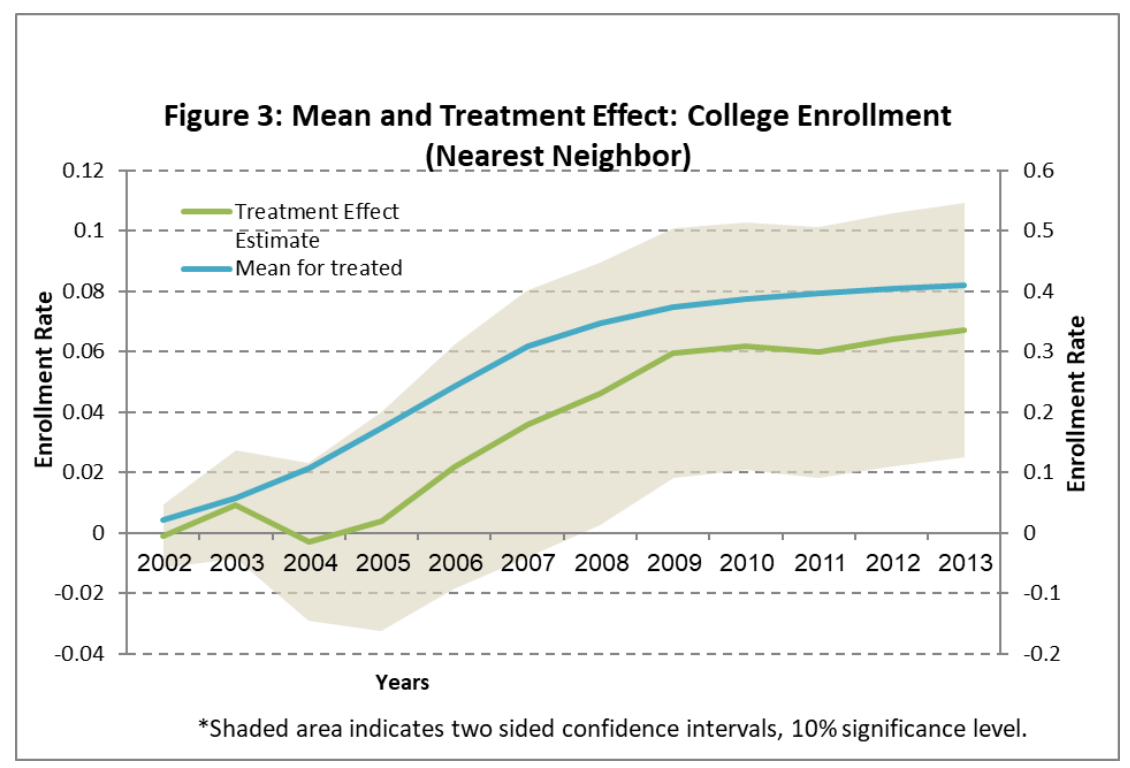

Figure 4: Mean and Treatment Effect: Any Post-Secondary Yeras of Schooling (Nearest Neighbor)

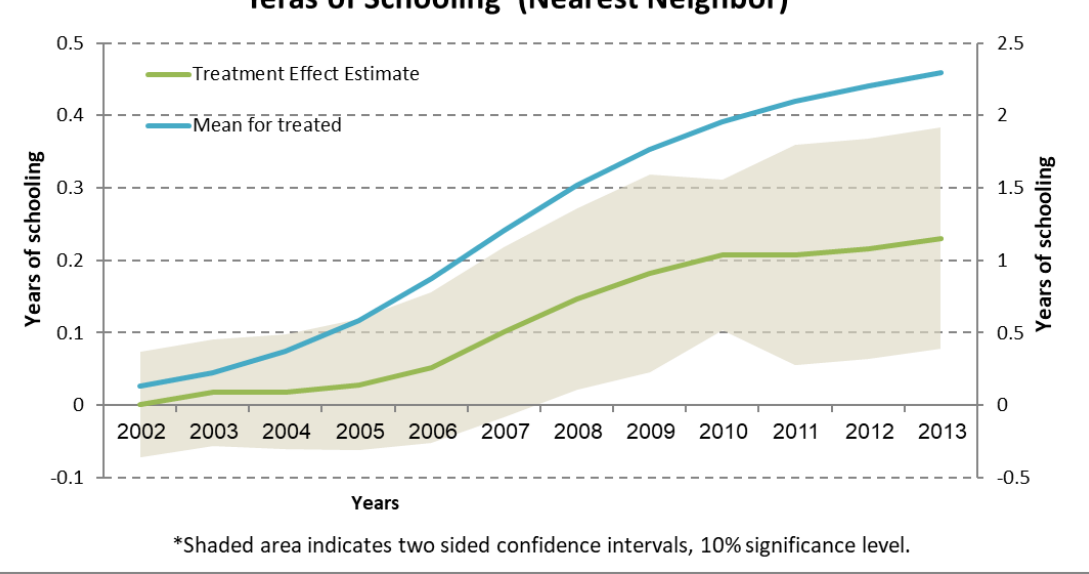

Figure 3A: Mean and Treatment Effect: College Enrollment (Kernel Matching)
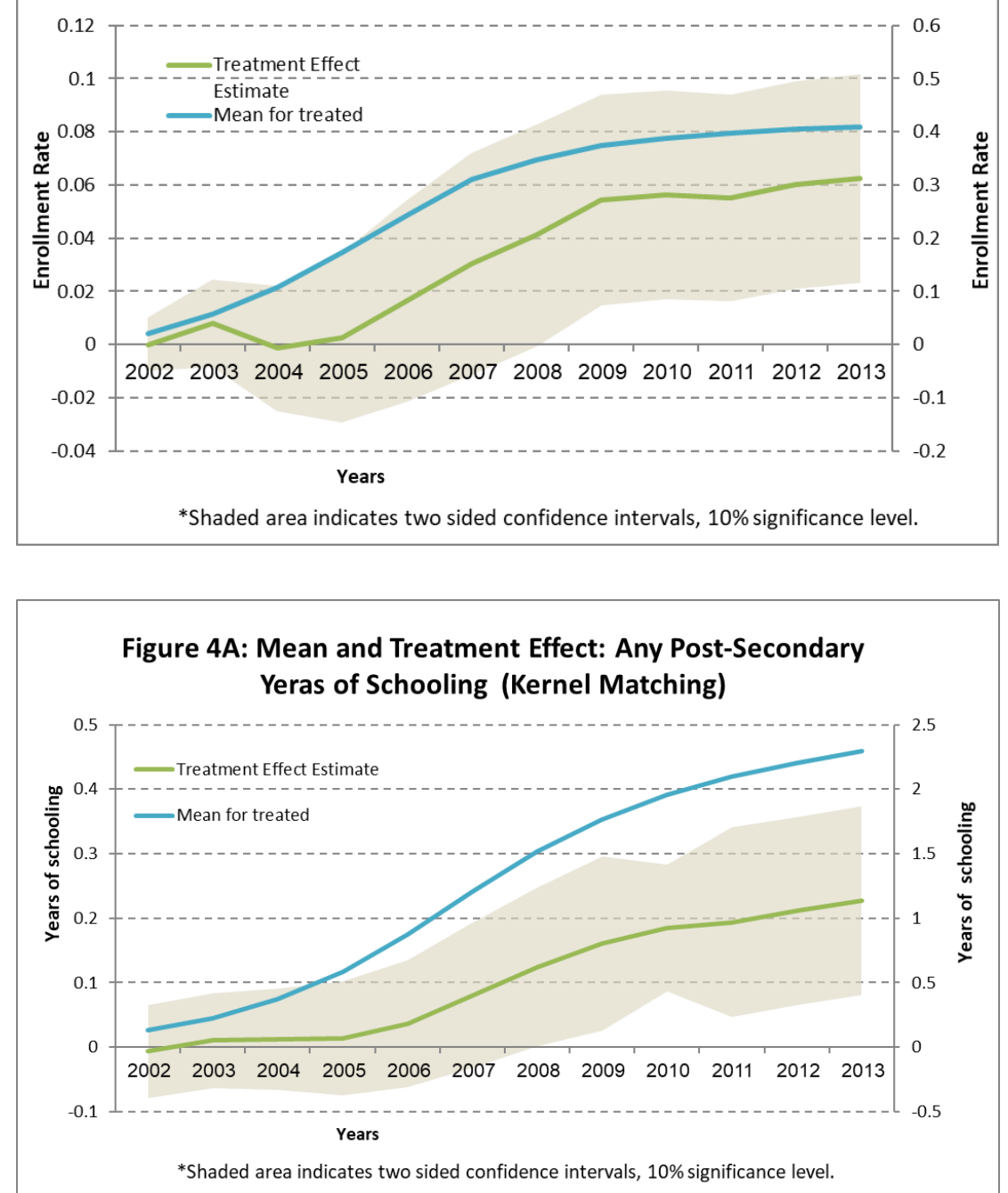

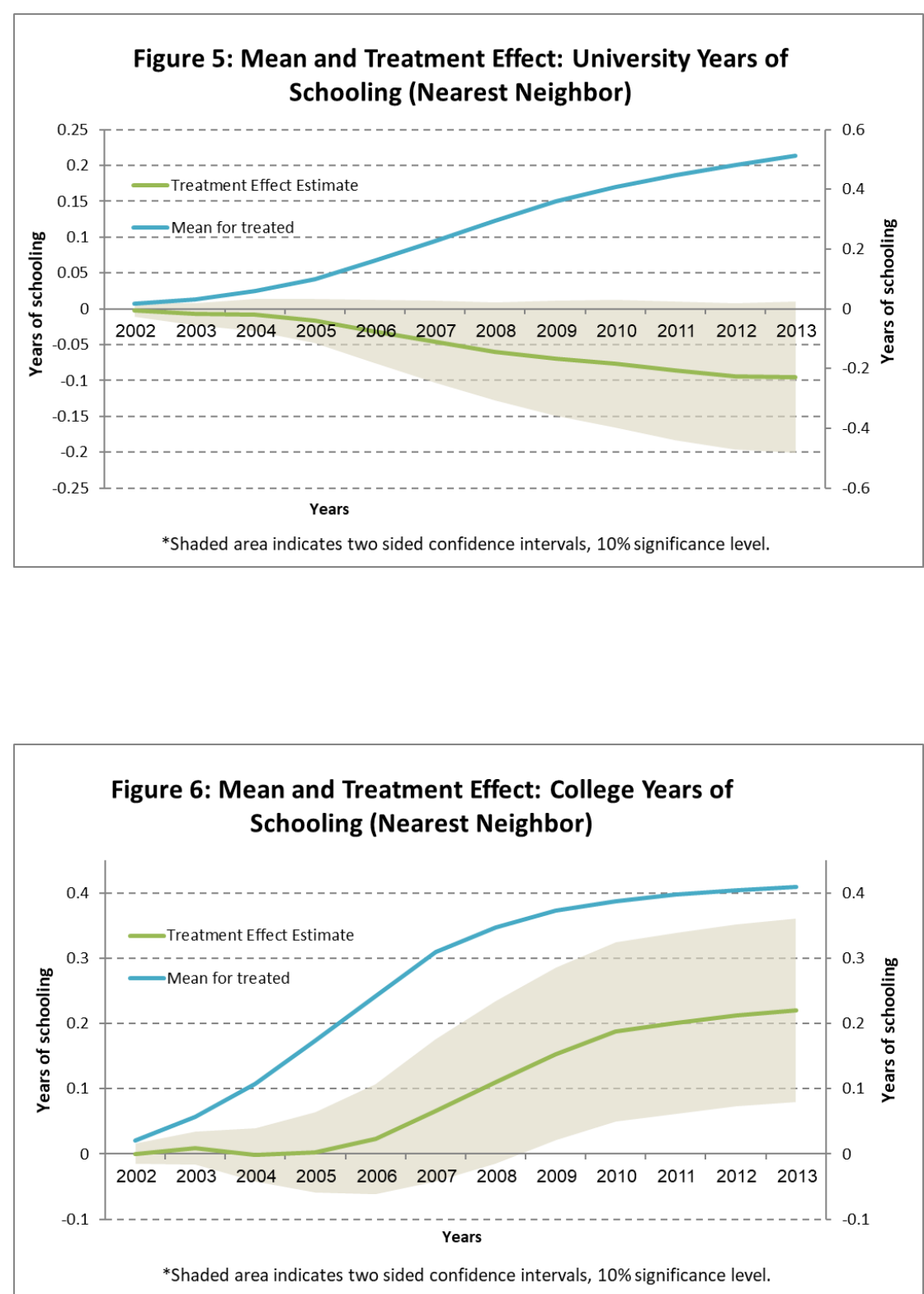

Figure 5A: Mean and Treatment Effect: University Years of Schooling (Kernel Matching)

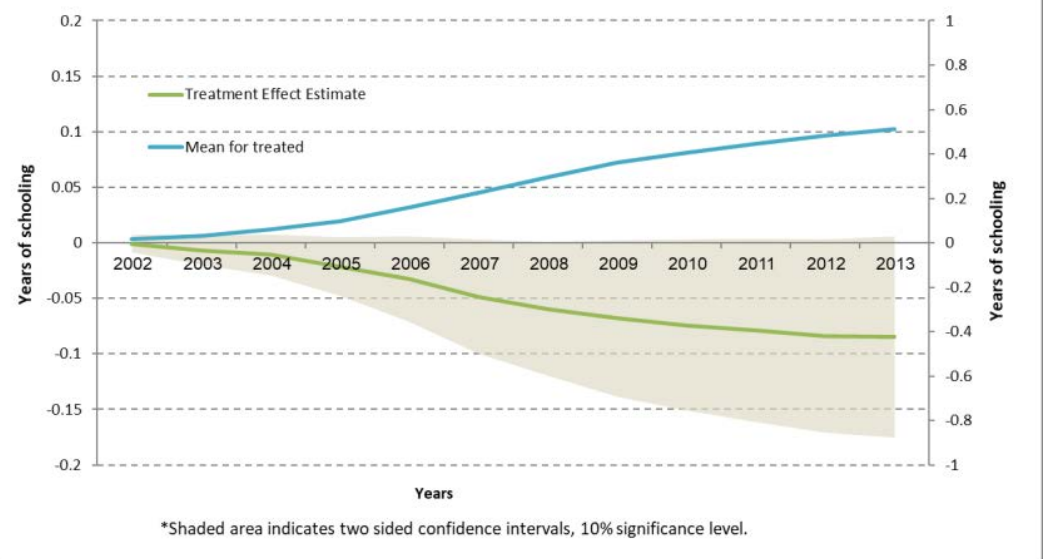

Figure 6A: Mean and Treatment Effect: College Years of Schooling (Kernel Matching)

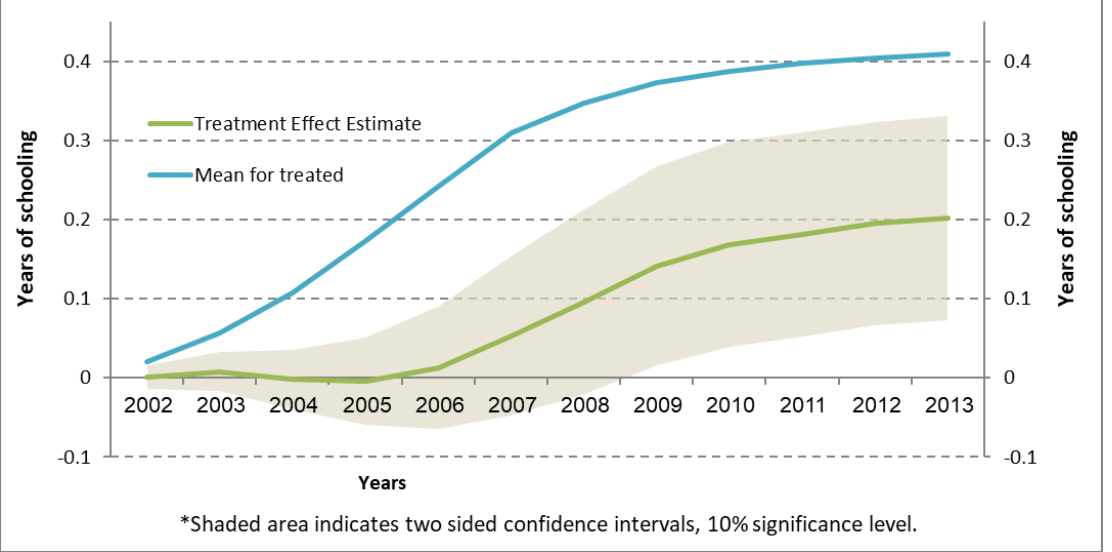



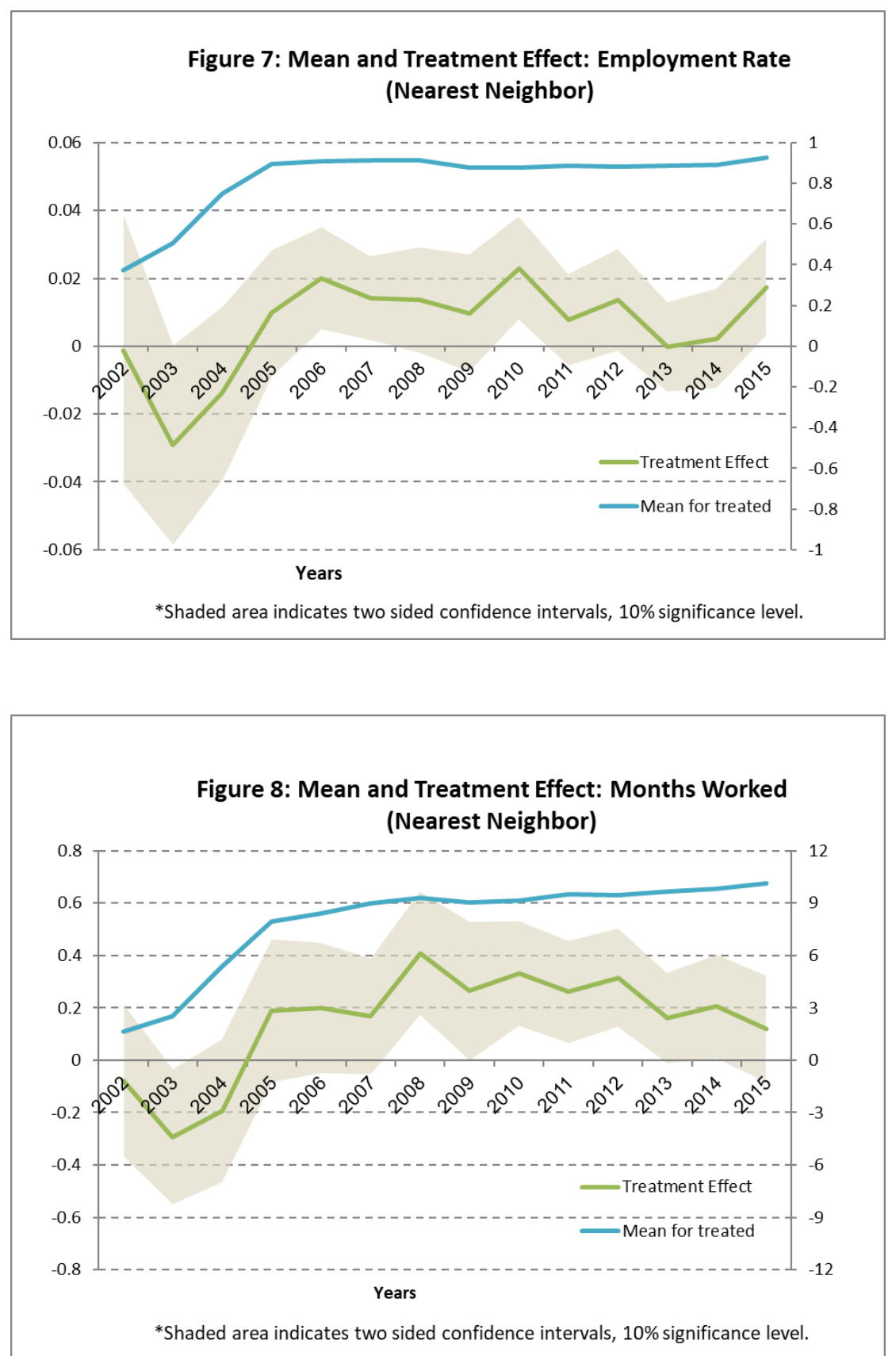

Figure 7A: Mean and Treatment Effect: Employment Rate (Kernel Matching)
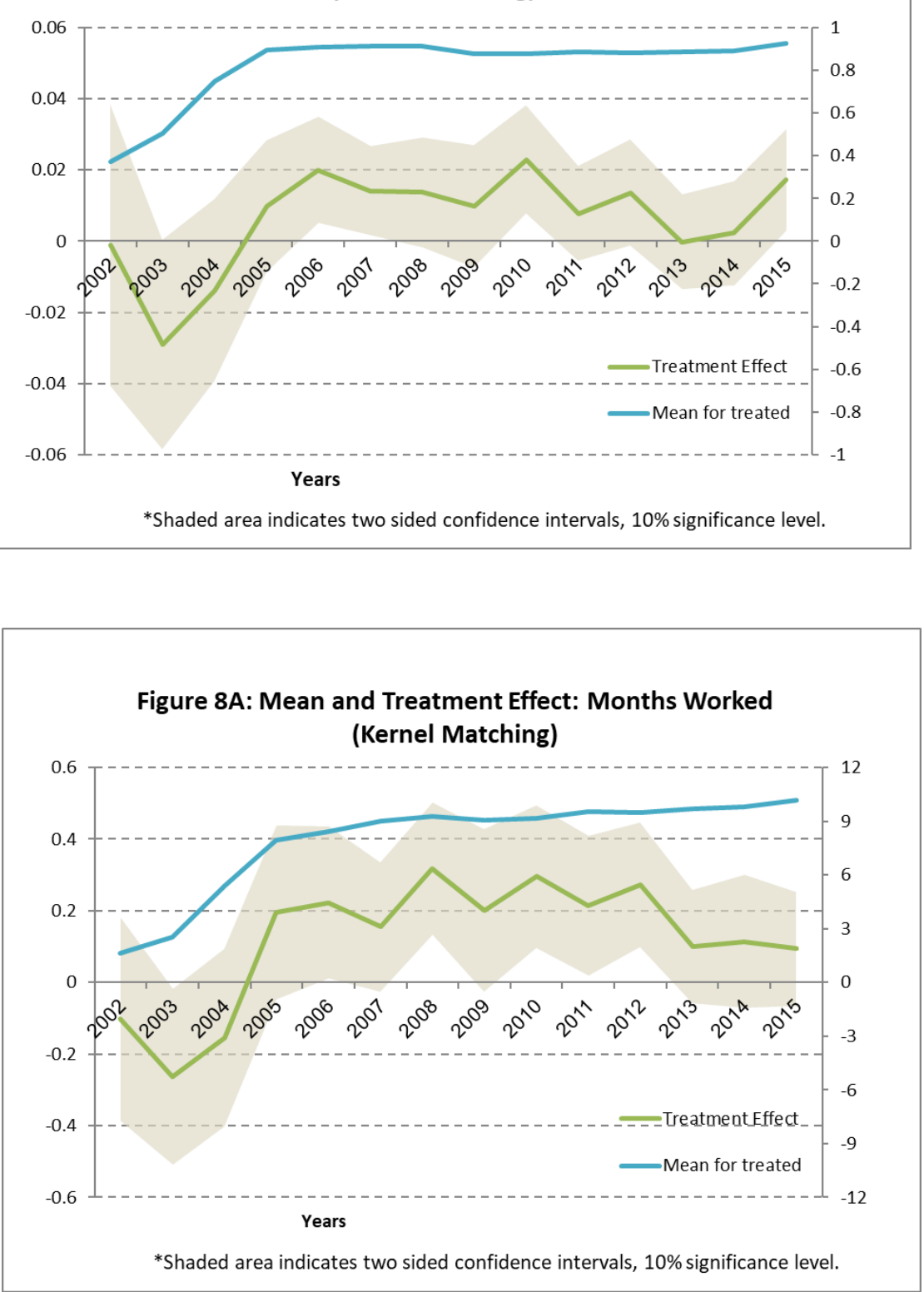
Figure 9: Mean and Treatment Effect: Annual Earnings - 2009 Prices NI Shekels (Nearest Neighbor)

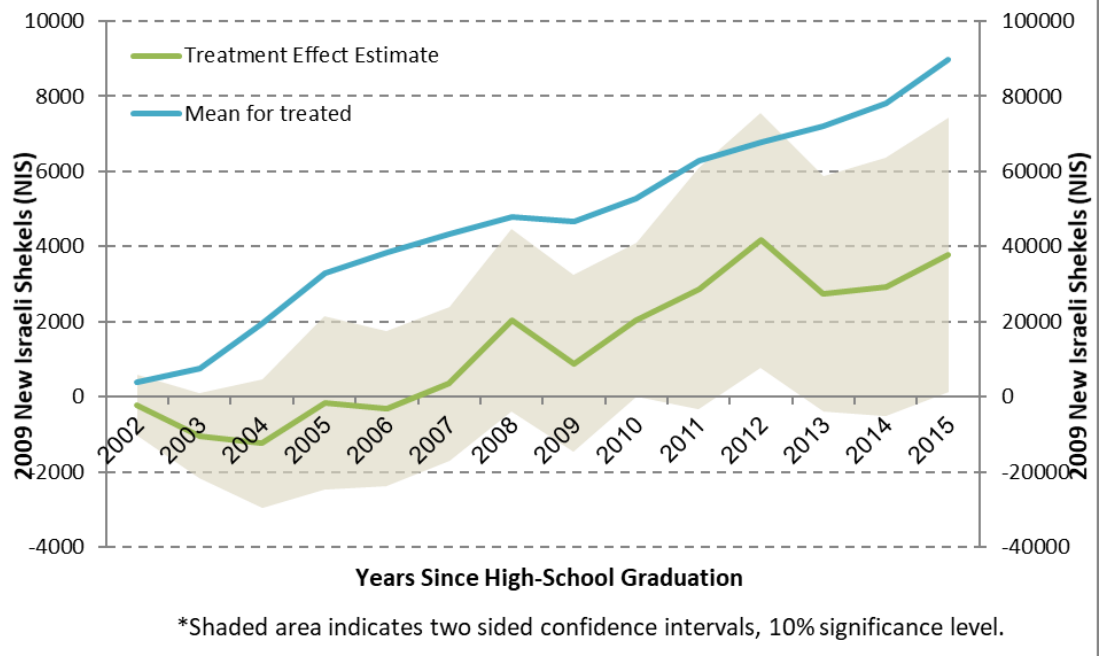

Figure 9A: Mean and Treatment Effect: Annual Earnings - 2009 Prices NI Shekels (Kernel Matching)

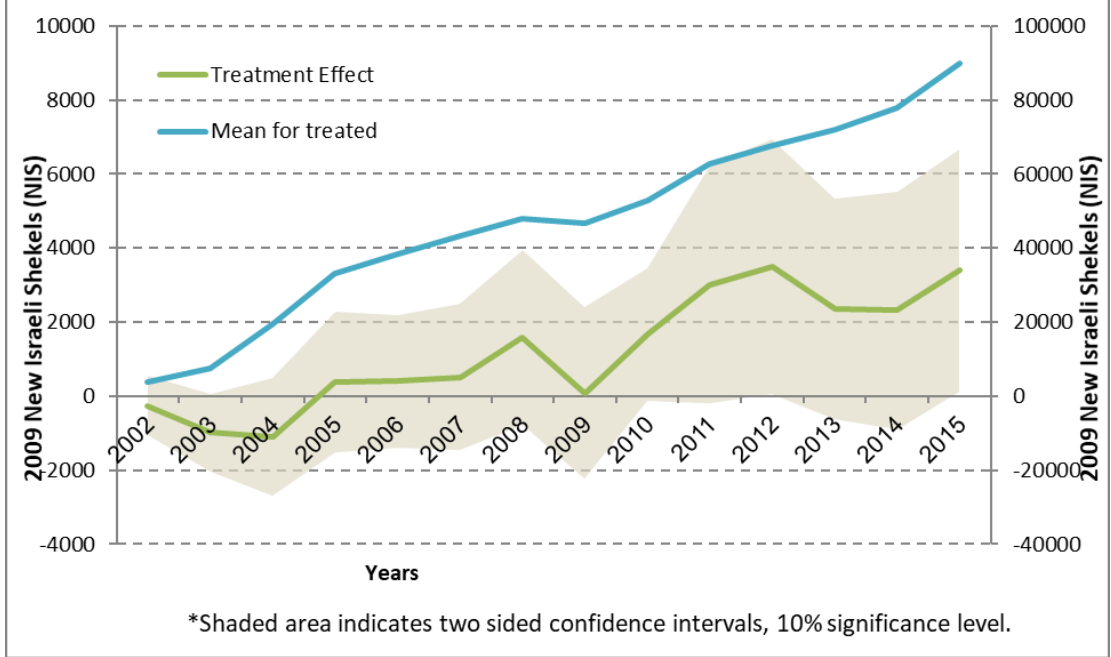


Figure A1: Program Participation Rate by School Size

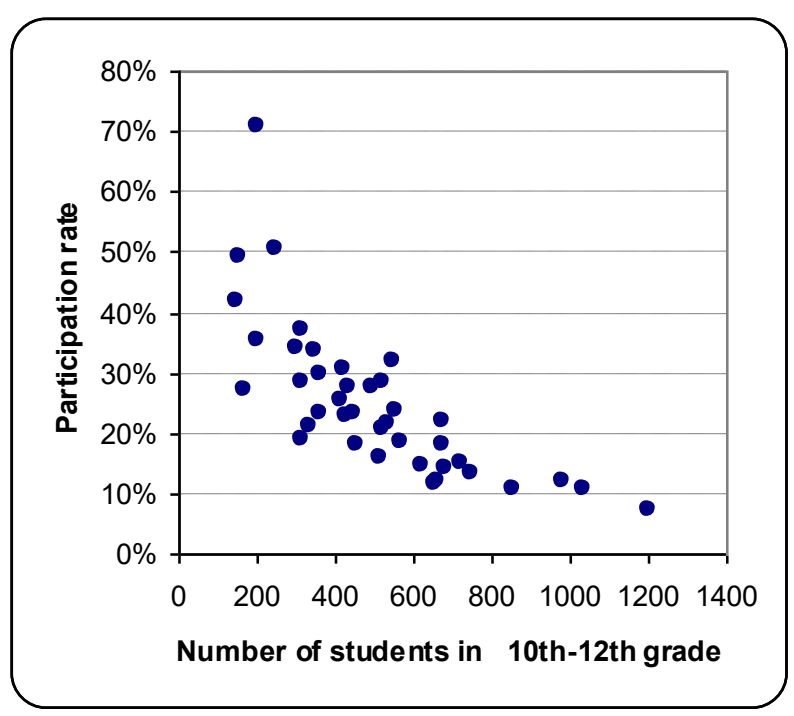

Figure A2: Program Participation Rate by Pre-Treatment Matriculation Rate

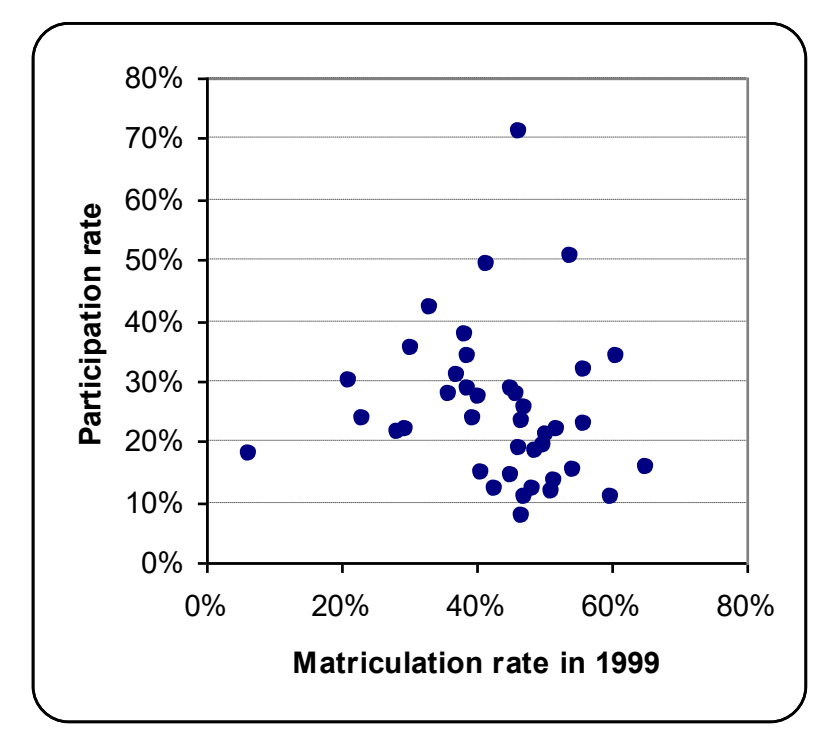

